\title{
Effectiveness of Yellow Maize Testers with Varying Resistance Reactions to Striga hermonthica for Evaluating the Combining Ability of Maize Inbred Lines
}

\author{
Degife Zebire ${ }^{1,2,3} \mathbb{D}$, Abebe Menkir ${ }^{1, *}$, Victor Adetimirin ${ }^{4}$, Wende Mengesha ${ }^{1} \mathbb{D}$, \\ Silvestro Meseka ${ }^{1}$ (D) and Melaku Gedil ${ }^{1}$ (D) \\ 1 International Institute of Tropical Agriculture (IITA), PMB 5320, Ibadan 200001, Nigeria; \\ asefadegife@gmail.com (D.Z.); w.mengesha@cgiar.org (W.M.); S.Meseka@cgiar.org (S.M.); \\ m.gedil@cgiar.org (M.G.) \\ 2 Pan African University Life and Earth Sciences Institute (including Health and Agriculture) \\ University of Ibadan, Ibadan 200284, Nigeria \\ 3 Department of Plant Science, College of Agricultural Sciences, Arba Minch University, \\ Arba Minch 4400, Ethiopia \\ 4 Department of Agronomy, University of Ibadan, Ibadan 200001, Nigeria; votimirin@yahoo.com \\ * Correspondence: A.Menkir@cgiar.org; Tel.: +234-803-3378-610
}

Received: 26 July 2020; Accepted: 22 August 2020; Published: 28 August 2020

\begin{abstract}
The choice of an appropriate tester is important for success in resistance hybrid breeding programs. Limited information is available on the most suitable testers that allow the selection of yellow endosperm maize inbred lines with good combining ability for resistance to witchweed (Striga hermonthica) and superior agronomic performance in hybrids targeted to areas infested with the parasite. Testcrosses of 30 Striga-resistant yellow endosperm maize inbred lines with three testers having varying levels of resistance to $S$. hermonthica were evaluated at Abuja and Mokwa in Nigeria under Striga-infested and non-infested conditions in 2018 and 2019. The lines $\times$ tester interaction was significant for grain yield under Striga infestation, indicating that the performance lines in testcrosses varied with the testers. The respective average general combining ability effect of lines and testers was 1.5 and 32.4 times greater than the corresponding specific combining ability effects under infestation, showing the greater importance of additive gene action controlling the performance of testcrosses under Striga infestation. The different testers exhibited a different capacity to discriminate among the test lines with the susceptible tester being the least effective. Most of the criteria used to determine the best tester favored the selection of the tolerant and resistant testers as promising candidates to identify superior Striga-resistant yellow endosperm inbred lines for the hybridization and development of resistant hybrids. The results of this study demonstrated that testers with a high frequency of desirable alleles were superior to the tester with a low frequency of favorable alleles in hybrid breeding programs for resistance to $S$. hermonthica.
\end{abstract}

Keywords: yellow maize lines; testers; testcrosses; coefficients of concordance; Striga hermonthica

\section{Introduction}

More than $90 \%$ of maize (Zea mays L.) produced globally is yellow, whereas more than $90 \%$ of the total maize produced in Africa is white [1]. The preference of yellow maize over white maize by African consumers is driven primarily by tradition [2]. At present, the demand for yellow maize is increasing in sub-Saharan Africa (SSA) because of the increasing demand for human consumption 
to address vitamin A deficiency as well as for animal feed as it gives a deep yellow coloration to egg yolks, poultry skin and animal fat that consumers consider healthy and fresh [3]. Breeding for yellow hybrids can then be effective to increase maize yield in SSA [4]. The yield advantage of hybrid maize over open-pollinated varieties (OPVs) is often over 15-100\% [5,6]. However, considerable yield gaps in maize are still common in sub-Saharan Africa as compared to other parts of the world due to biotic and abiotic factors as well as limited use of inputs and improved crop management practices [7-11]. Amongst the biotic factors, the parasitic weed Striga hermonthica (Del.) Benth inflicts severe damage to maize [12] and other cereal crops as a result of the nutrients and water loss in the host plant through parasitism [13]. Grain yield losses of up to $100 \%$ have been recorded in susceptible maize varieties and hybrids $[14,15]$. Considering the potential benefits of hybrids in increasing maize yields in Striga-infested areas, significant investments have been committed by the International Institute of Tropical Agriculture (IITA) towards the development and commercialization of high yielding and resistant hybrids [16,17]. In our breeding program, tolerance to Striga hermonthica has been regarded as the capacity of maize plants expressing less parasite-induced leaf scorching, better plant growth and ear development and higher grain yield notwithstanding its support of a large number of emerged parasites, whereas resistance to Striga has been described as the capacity of maize plants to support significantly less emerged Striga plants and produce significantly more grain yield than susceptible plants under parasite pressure [17-19]. The polygenic nature of the inheritance of traits associated with resistance to $S$. hermontica [20-22] prompted breeders at IITA to employ recurrent selection schemes to improve resistance source populations. Striga-resistant maize inbred lines with desirable agronomic attributes showing less parasite damage symptoms and supporting less emerged Striga plants have then been derived from these populations for developing resistant hybrids targeted to areas infested with the parasite $[17,18,21,23]$.

The relative performance of inbred lines in testcrosses with appropriate testers has proven useful to select inbred lines with good combining abilities and superior performance in hybrids. Hybrid maize breeding for resistance to S. hermonthica in International Institute of Tropical Agriculture (IITA) has commonly employed Striga-resistant inbred testers to evaluate the performance of new inbred lines in hybrid combinations under parasite pressure. However, a single type of tester may not completely fulfil the requirement of being the best in determining the breeding value of lines to express high levels of resistance across hybrid combinations. Given the ambiguity and inconsistency associated with the choice of the most appropriate tester [24], evaluating the relative importance of several types of testers will be important in resistance hybrid breeding programs [25-27].

Many studies have been conducted to identify and use the most appropriate tester in hybrid breeding [24,28-31]. Matzinger [28] and Russell [32] considered a desirable tester as one that is simple to use and maximizes genetic difference expressed among testcrosses of new inbred lines under evaluation. Several possibilities exist in choosing testers, including those with (i) a broad versus narrow genetic base, (ii) high versus low favorable allele frequency, (iii) high versus low yielding and (iv) use of many testers versus a single tester [24,33]. Consequently, identification of desirable testers and their discriminative ability remains an unresolved problem in crop breeding. Rawlings and Thompson [29] defined a good tester as one that differentiates efficiently among lines under test and classifies them correctly based on their relative performance in hybrid combinations. Matzinger [28] and Guimarães et al. [34] considered testers that elicit the greatest genetic variances among testcrosses as suitable for evaluating a set of inbred lines.

The line $\times$ tester mating scheme has been extensively used to determine the general combining ability (GCA) of maize inbred lines and their specific combining ability (SCA) effects [24,35]. This method has proven useful to identify superior parents of hybrids, classify inbred lines into heterotic groups and identify appropriate testers for use in a breeding program [36-38]. Rawlings and Thompson [29] suggested that a low-yielding tester possessing a low frequency of dominant alleles could provide a better discriminating capacity of the combining ability among maize inbred lines. Hallauer and Carena [39] recommended the use of testers with a high frequency of favorable alleles to identify the 
best lines with the highest specific combining ability. In sharp contrast, Fato et al. [40] found that a tester with a high frequency of favorable alleles for resistance to downy mildew (DM) disease in maize was better than a susceptible tester in discriminating inbred lines in terms of resistance to the disease under infection, days to anthesis and silking and grain yield. These authors, however, recommended the need for further studies to include more potential testers to improve breeding efficiency in resistance hybrid maize breeding program in Mozambique.

Identification of better testers has the potential for increasing the rate of genetic gain in resistance hybrid maize breeding programs [34]. It is not known if the most appropriate type of tester is dependent on the objectives of a breeding program. Limited information is available regarding the most suitable testers that permit selection of yellow endosperm maize inbred lines with good combining abilities and superior agronomic performance in hybrids for Striga-infested areas. The present study was, therefore, conducted to determine the effectiveness of yellow endosperm maize inbred line testers with diverse reactions to $S$. hermonthica for identifying lines with a high expression of resistance to the parasite in hybrid combinations.

\section{Materials and Methods}

\subsection{Genetic Materials}

Thirty yellow endosperm Striga-resistant maize inbred lines and three testers with varying levels of resistance to Striga developed at the International Institute of Tropical Agriculture (IITA) were used in this study (Table A1). Amongst the 30 lines, 22 were derived from two biparental crosses of elite Striga-resistant yellow maize inbred lines, while the remaining eight Striga-resistant lines were derived from a synthetic (ACR97SYN-Y), an early composite (TZE COMP5) and a late-maturing experimental variety (ACR97TZL-COMP1). The three testers were a Striga-tolerant line (TZISTR1207) derived from a backcross containing a temperate inbred line (B73) (T1), a Striga-resistant line (TZSTRI106) derived from a backcross containing perennial teosinte (Zea diploperennis) in its genome (T2), and a Striga-susceptible line (TZISTR1033) derived from a biparental cross between a temperate line (9450) and a line from Thailand (KI21) (T3). The 30 inbred lines were each crossed to the three testers to generate 90 testcrosses, which were evaluated along with two checks, one tolerant (8425-8) and one susceptible (8338-1) to the parasite.

\subsection{Experimental Sites and Striga Infestation Treatments}

The study was conducted under Striga-infested and non-infested conditions during the 2018 and 2019 cropping seasons at Abuja $\left(9^{\circ} 15^{\prime} \mathrm{N}\right.$ and $7^{\circ} 20^{\prime} \mathrm{E}$, with an altitude of 431 m.a.s.l.) and Mokwa $\left(9^{\circ} 21^{\prime} \mathrm{N}\right.$ and $5^{\circ} 1^{\prime} \mathrm{E}$, with an altitude of $188 \mathrm{~m}$.a.s.l.), Nigeria is where Striga is endemic. Annual rainfall in Abuja was 1739 in 2018 and $2031 \mathrm{~mm}$ in 2019; respective values in Mokwa were 1152 and $993 \mathrm{~mm}$. The soil at Abuja was sandy and had $0.5 \mathrm{~g} \mathrm{~kg}^{-1} \mathrm{~N}, 68.99 \mathrm{mg} \mathrm{kg}^{-1} \mathrm{P}$ and $0.25 \mathrm{cmol} \mathrm{kg}^{-1} \mathrm{k}$ total nitrogen, phosphorus and potassium content, respectively, while the soil at Mokwa was sandy loam with $0.4 \mathrm{~g} \mathrm{~kg}^{-1}$ nitrogen, $31.5 \mathrm{mg} \mathrm{kg}^{-1} \mathrm{P}$ and $0.10 \mathrm{cmol} \mathrm{kg}^{-1} \mathrm{~K}$.

\subsection{Trial Design and Field Management Practices}

The 92 testcrosses were planted in a $23 \times 4$ alpha lattice design with two replications in a criss-cross arrangement [41]. Each hybrid was planted in adjacent infested and non-infested strips, which were located opposite to each other and separated by a $1.5 \mathrm{~m}$ alley. Within each strip, a hybrid was planted in a $4 \mathrm{~m}$-long row with an inter-row spacing of $0.75 \mathrm{~m}$ and an intra-row spacing of $0.25 \mathrm{~m}$. The infested row of a hybrid was planted directly opposite to the non-infested row to obtain precise estimates of yield loss attributable to $S$. hermonthica damage [22]. Plots consisted of single rows, each $4 \mathrm{~m}$ long with $0.75 \mathrm{~m}$ between rows. The non-infested rows were treated with ethylene two weeks before planting to eliminate any potential S. hermonthica seeds present in the soil. The S. hermonthica seeds used for infested plots in each year were collected in the previous year from farmers' sorghum fields from 
each of the locations. S. hermonthica infestation was carried out by applying $8.5 \mathrm{~g}$ of sand-mixed S. hermonthica seed inoculum into holes of about $6 \mathrm{~cm}$ depth and $10 \mathrm{~cm}$ width spaced $0.25 \mathrm{~m}$ apart. The estimated number of germinable Striga seeds per hill was 3000. Two maize seeds of each genotype were placed into the holes infested with the sand mixed with $S$. hermonthica seeds and covered with soil. Plots were thinned to one plant per hill two weeks after emergence to attain a population density of 53,333 plants per ha. Fertilizer was applied as NPK (15-15-15) at the rate of $30 \mathrm{~kg}$ per ha N, $60 \mathrm{~kg}$ per ha $\mathrm{P}$ and $60 \mathrm{~kg}$ per ha $\mathrm{K}$ at planting and additional $30 \mathrm{~kg} \mathrm{~N}$ per ha was applied as urea four weeks later. Weeds other than S. hermonthica were manually removed throughout the cropping season.

\subsection{Maize Traits Measured}

Data collected in both Striga-infested and non-infested conditions included plant stand, days to $50 \%$ anthesis, days to $50 \%$ silking, plant height, ear aspect and grain yield. Days to $50 \%$ anthesis and $50 \%$ silking were recorded as the number of days from planting to when $50 \%$ of the plants in a plot shed pollen and showed silk extrusion, respectively. Anthesis-silking interval was calculated as the difference between days to $50 \%$ silking and days to $50 \%$ anthesis. Plant height was measured in $\mathrm{cm}$ as the distance from the base of the plant to the height of the first tassel branch. Ear aspect was scored on a 1 to 5 scale, where $1=$ clean, uniform and large ears, and $5=$ rotten, variable and small ears. All ears harvested from each plot were shelled to determine per cent moisture, which was used to adjust grain yield adjusted to $15 \%$ moisture. Host plant damage symptoms were visually rated in each infested row at 8 and 10 weeks after planting (WAP) using a scale of 1 to 9 , where $1=$ no visible host plant damage symptom, and $9=$ all leaves completely scorched, resulting in premature death [20]. The number of emerged S. hermonthica plants in each infested row was counted at 8 and $10 \mathrm{WAP}$ and divided by the number of plants to obtain the average number of emerged Striga plants per maize plant. At harvest, the total number of plants and ears was counted in each Striga-infested and non-infested plot and these were used to calculate the number of ears per plant.

Other data collected in only non-infested plots include ear height, which was measured in $\mathrm{cm}$ as the distance from the base of the plant to the height of the node bearing the upper ear, and husk cover, rated on a 1 to 5 scale, where $1=$ husks tightly arranged and extended beyond the ear tip, and $5=$ loose husks with ear tips exposed. Plant aspect was rated on a scale of 1 to 5 , where $1=$ excellent plant type with large and uniform ears, low ear placement, shorter plants, resistance to foliar diseases and little or no stalk and root lodging, and 5 = plants with small and variable ears, high ear placement, tall plants, susceptible to foliar diseases, with severe stalk and root lodging. Ear rot was rated on a scale of 1 to 5 , where $1=$ little or no visible rotting of the ears, and $5=$ extensive rotting of the ears.

\subsection{Data Analysis}

Each location-year combination was considered a test environment. Analysis of variance was carried out following the procedure for line $\times$ tester as described by Singh and Chaudhary [42] using the PROC MIXED procedure in SAS version 9.4 [43] by excluding checks. In the general analysis, the GLM procedure was used across environments for each of the Striga-infested and non-infested conditions. Environment, replication (environment) and block (replication $\times$ environments) were considered random effects while genotypes were regarded as fixed effects. Testcross mean square was partitioned into lines, testers and line $\times$ tester mean squares, while testcross $\times$ environment means the square was also partitioned into line $x$ environment, tester $\times$ environment and line $x$ tester $\times$ environment. Two orthogonal contrasts, corresponding to the two degrees of freedom for the testers, were conducted as $1 / 2(\mathrm{~T} 1+\mathrm{T} 2)$ vs. $\mathrm{T} 3$ and $\mathrm{T} 1 \mathrm{vs}$. $\mathrm{T} 2$.

The mixed model used for the analysis was:

$$
Y_{i j k}=\mu+\operatorname{Rep}_{k}+\operatorname{Blk}\left(\operatorname{Rep}_{k}\right)+l_{i}+t_{j}+l_{i} \times t_{j}+l_{i} \times e_{k}+t_{j} \times e_{k}+l_{i}+t_{j} \times e_{k}+e i j k,
$$


where $Y_{\mathrm{ijk}}=$ observed value of a trait; $\mu=$ overall mean; $\operatorname{Repk}=$ replication $(\mathrm{k}=1,2) ; \operatorname{Blk}\left(\operatorname{Rep}_{\mathrm{k}}\right)=$ random effect of block nested in replication $k ; l_{i}=$ line effect $(I=1,2, \ldots 30) ; t_{j}=$ tester effect $(j=1,2,3)$; $l_{i} \times t_{j}=$ interaction effect of the $i^{\text {th }}$ line and the $j^{\text {th }}$ tester; $l_{i} \times e_{k}=$ interaction effect of the $i^{t^{\text {th }}}$ line and the $\mathrm{k}^{\text {th }}$ environment; $\mathrm{t}_{\mathrm{j}} \times \mathrm{e}_{\mathrm{k}}=$ interaction effect of the $\mathrm{j}^{\text {th }}$ tester and the $\mathrm{k}^{\text {th }}$ environment; $\mathrm{l}_{\mathrm{i}}+\mathrm{t}_{\mathrm{j}} \times$ $\mathrm{e}_{\mathrm{k}}=$ interaction effect of the $\mathrm{i}^{\text {th }}$ line, the $\mathrm{j}^{\text {th }}$ tester and the $\mathrm{k}^{\text {th }}$ environment; $=$ random experimental error.

The average relative yield loss due to Striga infection for each tester was computed based on the differences in performance between Striga-infested and non-infested conditions and then the differences were divided by the performance under the non-infested condition and expressed in percentage. The efficiency of testers was first determined based on the genetic variance estimates obtained from the analysis of variance of testcross LSMEANS across the four environments for the testers [44]. Second, the testcrosses and inbred lines LSMEANS and best linear unbiased prediction (BLUPs) across environments were ranked using PROC RANK in SAS 9.4 [43]. The resulting ranks were then used to calculate Kendall's coefficient of concordance (W) [45] to assess the similarity of the rank order of the 30 inbred lines and their testcrosses for infested and non-infested conditions. The ranking was presented in descending order were the best performing combinations came first and vice versa, but for Striga damage rating, the ranking was in ascending order, i.e., inbred lines with low score value ranked first and vice versa. The principal component analysis was computed in SAS using the correlation matrix of trait means-centered averaged over environments to determine the significant combination of traits to the performance of testcrosses of the three testers under both infested and non-infested conditions. Correlation analyses were conducted between each of the first two principal component axes (PC1 and PC2) scores for the 90 testcrosses to identify a combination of traits that significantly contributed to each component axis. Further, the PC1 and PC2 axes scores were plotted to assess the relative grouping of the testcrosses involving the three testers. General combining ability (GCA) and specific combining ability (SCA) effects were tested for significance by dividing the GCA and SCA values by their respective standard error, and comparing the result on $t$-value with tabular $\mathrm{t}$-value at $p \leq 0.05$ was used to determine the level of significance. The ratio of GCA to SCA was used to determine the relative importance of additive to non-additive gene effects using the formula of Baker [46] described as:

$$
\text { Relative contribution }=\frac{2 \sigma 2 g c a}{2 \sigma 2 g c a+\sigma 2 s c a}
$$

\section{Results}

\subsection{Variation among Testcrosses}

Under Striga infestation, environment and testcrosses effects were significant $(p<0.05)$ for all the traits, except anthesis-silking interval for testcrosses (Table 1). The GCA effects due to lines and testers were significant $(p<0.01)$ for all traits except anthesis-silking interval and ears per plant for lines, indicating that the additive genetic effects were important in controlling most of the traits. Line $\times$ tester interactions were significant $(p<0.05)$ for only grain yield and Striga damage rating at $10 \mathrm{WAP}$, indicating that the non-additive genetic effects were less important in controlling most traits measured in this trial. Testcross $\times$ environment interaction was significant $(p<0.01)$ for all traits except for grain yield, Striga emergence count at $8 \mathrm{WAP}$ and ear aspect. Line $\times$ environment interactions were significant $(p<0.05)$ for all traits except for grain yield, plant height, Striga count at $10 \mathrm{WAP}$, ears per plant and ear aspect. Tester $\times$ environment interaction was, however, significant $(p<0.05)$ for all traits measured. Line $\times$ tester $\times$ environment interaction was significant $(p<0.05)$ for only Striga damage rating at 10 WAP (Table 1). Orthogonal contrasts between $1 / 2(\mathrm{~T} 1+\mathrm{T} 2)$ vs. T3 and T1 vs. T2 were significant $(p<0.01)$ for most or all of the traits recorded under the Striga-infested condition. It is interesting to note that the differences between T1 and T2 were not significant for grain yield and Striga count.

Under the Striga-non-infested condition, environment and testcross mean squares were significant $(p \leq 0.01)$ for all the traits except anthesis-silking interval for testcross (Table 2). Line and tester GCA 
effects were significant for all traits except for anthesis-silking interval of both lines and testers, and plant aspect and ears per plant for the testers. Line $\times$ tester interaction was not significant for grain yield and five other traits under the non-infested condition, but significant for ear height, husk cover, ear aspect score and ears per plant, and testcross $\times$ environment interaction was significant for all traits $(p \leq 0.05)$ except for grain yield, anthesis-silking interval, plant height, ear height and plant aspect score. Line $\times$ environment interaction was significant $(p<0.001)$ for all traits except grain yield, ears per plant, plant aspect and ear height. For tester $\times$ environment interaction, eight of the traits were significant; only days to $50 \%$ silking and anthesis-silking interval were not significant. Only ears per plant was significant for line $\times$ tester $\times$ environment interaction (Table 2$)$. The contrasts between $1 / 2(\mathrm{~T} 1+\mathrm{T} 2) \mathrm{vs}$. T3 and T1 vs. T2 were significant $(p<0.01)$ for most traits measured under the non-infested condition (Table 2).

Under Striga infestation, genetic variances for the tolerant tester (T1) were highest for three of the 11 traits and these include two of the most important traits under Striga viz. grain yield and Striga count at 10 WAP. Genetic variances of the resistant tester (T2) were highest and significant for six traits, one of which (Striga rating at $8 \mathrm{WAP}$ ) was similar in value to the genetic variance obtained for the susceptible tester (Tables 3 and A2). The susceptible tester (T3) had the highest genetic variance in two other traits viz. Striga count at 8 WAP and ears per plant.

Under the Striga-non-infested condition, the resistant tester had the highest and significant genetic variances in 6 of the 10 traits studied, while the tolerant tester had the highest values in four traits. The susceptible tester did not have the highest value in any traits. As under the Striga-infested condition, the highest genetic variance for grain yield was obtained with the tolerant tester. Overall, the tolerant and resistant testers had the highest genetic variances for many traits than the susceptible tester under Striga-infested and non-infested conditions. 
Table 1. Mean squares for grain yield and other traits of testcrosses of yellow maize inbred lines under the Striga-infested condition in four environments.

\begin{tabular}{|c|c|c|c|c|c|c|c|c|c|c|c|c|}
\hline \multirow[t]{2}{*}{ Source of Variation } & \multirow[t]{2}{*}{ DF } & \multirow{2}{*}{$\begin{array}{l}\text { Grain Yield } \\
\text { (Kg/ha) }\end{array}$} & \multirow[t]{2}{*}{ Silking } & \multirow[t]{2}{*}{ Anthesis } & \multirow{2}{*}{$\begin{array}{l}\text { Anthesis-Silking } \\
\text { Interval } \\
\text { days }\end{array}$} & \multirow{2}{*}{$\begin{array}{l}\text { Plant } \\
\text { Height } \\
\text { (cm) }\end{array}$} & \multicolumn{2}{|c|}{$\begin{array}{c}\text { Striga Damage Rating } \\
(1-9)\end{array}$} & \multicolumn{2}{|c|}{$\begin{array}{c}\text { Emerged Striga Count } \\
\text { (No.) }\end{array}$} & \multirow{2}{*}{$\begin{array}{c}\text { Ear } \\
\text { Aspect } \\
(1-5)\end{array}$} & \multirow{2}{*}{$\begin{array}{c}\text { Ear Per } \\
\text { Plant } \\
\text { No. }\end{array}$} \\
\hline & & & & & & & 8 WAP & 10 WAP & 8 WAP & $10 \mathrm{WAP}$ & & \\
\hline Env & 3 & $468,026,713 \dagger$ & $5509.5+$ & $5663.3+$ & $5.4 \dagger$ & $96,047.1+$ & $76.8+$ & $208.0+$ & $133,089.7+$ & $486,970.1 \dagger$ & $29.6+$ & $1.70 \dagger$ \\
\hline Rep & 1 & $9,969,947 * * *$ & 1.0 & 0.2 & 0.39 & 81.6 & 1.2 & 0.1 & $4005.6 * *$ & $25,521.1+$ & $0.6 *$ & 0.01 \\
\hline REP (Env) & 3 & $955,1116+$ & $17.4+$ & $9.2 * * *$ & $1.5^{* *}$ & $1056.9+$ & $2.2 *$ & 2.7 & $3122.3+$ & $22,756.8+$ & $0.7^{* *}$ & $0.07^{* *}$ \\
\hline Block $($ Env × Rep) & 176 & $1,506,294+$ & $4.7+$ & $3.9+$ & $0.5^{* *}$ & $348.0+$ & 0.9 & 1.2 & $797.9+$ & $1960.4 \dagger$ & $0.3+$ & 0.02 \\
\hline Genotype & 91 & $2,375,057+$ & $17.3+$ & $15.4+$ & 0.37 & $441.3+$ & $2.4+$ & $3.9+$ & $940.1+$ & $1427.0 \dagger$ & $0.5+$ & $0.06+$ \\
\hline Testcross & 89 & $3,214,385+$ & $25.41+$ & $22.31+$ & 0.46 & $623.05+$ & $2.92+$ & $4.86+$ & $1249.47 \dagger$ & $1933.8^{* * *}$ & $0.53+$ & $0.05+$ \\
\hline Line (GCA) & 29 & $2,583,503 * * *$ & $39.9+$ & $34.7+$ & 0.57 & $1070.6+$ & $2.97+$ & $4.49+$ & $2152.19+$ & $2770.88^{* * *}$ & $0.64+$ & 0.08 \\
\hline Tester (GCA) & 2 & $55,710,267+$ & $426.0+$ & $389.1+$ & $1.48+$ & $6429.2+$ & $57.4+$ & $95.4+$ & $5957.6+$ & $4949.4 *$ & $6.4+$ & $0.7^{* *}$ \\
\hline 1/2(T1 + T2) vs. $\mathrm{T} 3$ & 1 & $109,971,212.4+$ & $695.8+$ & $648.0 \dagger$ & 0.9 & $7200.3+$ & $107.8+$ & $158.7+$ & $9713.6+$ & $9005.0 * *$ & $7.1 \dagger$ & $1.07+$ \\
\hline T1 vs. T2 & 1 & $1,449,321.6$ & $169.2+$ & $130.2+$ & $2.6^{*}$ & $5658.1+$ & $7.0^{* *}$ & $32.0+$ & 2201.6 & 893.8 & $5.6+$ & $0.18^{* *}$ \\
\hline Line $\times$ Tester $(\mathrm{SCA})$ & 58 & $1,719,623$ ** & 4.1 & 3.5 & 0.38 & 199.1 & 1.02 & 1.93 ** & 635.76 & 1411.21 & 0.28 & 0.07 \\
\hline Genotype $\times$ Env & 273 & 793,185 * & $2.9^{* * *}$ & $2.7+$ & $0.42 *$ & 127.4 & 0.8 & $1.7^{* *}$ & 350.3 & 848.2 & 0.2 & 0.02 \\
\hline Testcross $\times$ Env & 267 & $1,131,521$ & $4.18^{* *}$ & $3.87^{* * *}$ & $0.47^{*}$ & 244.9 & $1.2^{* * *}$ & $2.2 \dagger$ & 609.1 & $1420.2 * *$ & 0.23 & $0.02 * *$ \\
\hline Line $\times$ Env & 87 & $1,181,929$ & $5.7^{* * * *}$ & $5.4+$ & $0.64^{* * *}$ & 272.9 & $1.53+$ & $2.40+$ & $716.15^{*}$ & 1298.8 & 0.3 & 0.11 \\
\hline Tester $\times$ Env & 6 & $3,695,027 * *$ & $11.94 * *$ & $15.7 \dagger$ & $1.01 *$ & $682.8^{* *}$ & $8.2+$ & $14.0 \dagger$ & $1304.0 *$ & $2683.1 *$ & $1.5 \dagger$ & $0.32 * *$ \\
\hline Line $\times$ Tester $\times$ Env & 174 & $1,017,921$ & 3.2 & 2.7 & 0.37 & 215.7 & 0.7 & $1.7^{* *}$ & 531.7 & 1437.3 & 0.2 & 0.1 \\
\hline Error & 359 & $1,108,721$ & 3.4 & 2.8 & 0.39 & 219.8 & 0.8 & 1.2 & 535 & 1240.5 & 0.2 & 0.1 \\
\hline Repeatability & & 0.74 & 0.87 & 0.86 & 0.0 & 0.77 & 0.73 & 0.65 & 0.68 & 0.49 & 0.69 & 0.76 \\
\hline $\mathrm{CV}$ & & 23.2 & 2.4 & 2.3 & 29.6 & 6.7 & 24.3 & 20.8 & 60 & 52.1 & 13.1 & 14.6 \\
\hline
\end{tabular}


Table 2. Mean squares for grain yield and other traits of testcrosses of yellow maize inbred lines under the Striga-non-infested condition in four environments.

\begin{tabular}{|c|c|c|c|c|c|c|c|c|c|c|c|}
\hline Source of Variation & DF & Grain Yield & Silking & Anthesis & $\begin{array}{l}\text { Anthesis-Silking } \\
\text { Interval }\end{array}$ & $\begin{array}{l}\text { Plant } \\
\text { Height }\end{array}$ & Ear Height & $\begin{array}{l}\text { Husk } \\
\text { Cover }\end{array}$ & $\begin{array}{c}\text { Pant } \\
\text { Aspect }\end{array}$ & Ear Aspect & $\begin{array}{c}\text { Ear per } \\
\text { Plant }\end{array}$ \\
\hline & & $(\mathrm{Kg} / \mathrm{ha})$ & & & days & $(\mathrm{cm})$ & $(\mathrm{cm})$ & Score (1-5) & Score (1-5) & Score (1-5) & No. \\
\hline Env & 3 & $323,822,482.5+$ & $5968.5+$ & $6276.0+$ & $15.12+$ & $81,170.4+$ & $80,201.7+$ & $13.5+$ & $45.3+$ & $28.6+$ & $0.31+$ \\
\hline Rep & 1 & $163,309.4$ & 0.1 & 0.2 & 0.01 & $1347.4+$ & $478.6^{* *}$ & 0.2 & $2.6+$ & 0.002 & 0.024 \\
\hline REP (Env) & 3 & $1,678,492 *$ & $18.4+$ & $7.2^{* * *}$ & $2.6^{* * *}$ & $566.9^{* * *}$ & $417.3+$ & $1.4^{* * *}$ & 0.25 & 0.12 & 0.02 \\
\hline Block $($ Env $\times$ Rep $)$ & 176 & $2,620,737.7+$ & $5.3+$ & $4.1+$ & $0.6^{* * *}$ & $393.1+$ & $247.0+$ & $0.3^{*}$ & $0.24 * *$ & $0.29+$ & 0.016 \\
\hline Genotype & 91 & $2,033,955.6+$ & $16.1+$ & $14.5+$ & 0.45 & $439.1+$ & $214.5+$ & $0.3^{* *}$ & $0.2 *$ & $0.3+$ & $0.02 *$ \\
\hline Testcross & 89 & $2,865,918.4+$ & $23.10+$ & $20.90+$ & 0.57 & $727.25+$ & $385.28+$ & $0.44^{* * *}$ & 0.26 * & $0.51+$ & $0.021 * *$ \\
\hline Line (GCA) & 29 & $2,641,094.2 *$ & $36.2+$ & $31.2+$ & 0.68 & $1296.3+$ & $719.2+$ & $0.9+$ & $0.4^{* *}$ & $0.4^{* * *}$ & 0.024 * \\
\hline Tester (GCA) & 2 & $39,634,973.7+$ & $391.0+$ & $377.9+$ & 0.28 & $4107.4+$ & $579.8^{*}$ & $3.5+$ & 0.1 & $7.8+$ & 0.018 \\
\hline 1/2(T1 + T2) vs. T3 & 1 & $49,033,386.9+$ & $429.5+$ & $433.6+$ & 0.01 & $2849.9+$ & 147.1 & 0.002 & 0.04 & $2.0 * * *$ & 0.01 \\
\hline T1 vs. T2 & 1 & $3,852,188.78 *$ & $118.3+$ & $94.9+$ & 1.28 & $1917.4^{* * *}$ & 254.5 & $8.26+$ & $3.9^{* * *}$ & $5.2+$ & 0.04 \\
\hline Line $\times$ Tester $(S C A)$ & 58 & $1,710,433$ & 4.1 & 3.6 & 0.52 & 318.1 & $208.6^{*}$ & $0.3^{* *}$ & 0.2 & $0.29 *$ & $0.02 *$ \\
\hline Genotype $\times$ Env & 273 & $880,288.8^{* * *}$ & $2.8^{* * *}$ & $2.5^{* * *}$ & 0.46 & $105.3 *$ & $70.0^{* *}$ & $0.4+$ & 0.2 & $0.2^{* *}$ & 0.019 \\
\hline Testcross $\times$ Env & 267 & $1,510,982.2$ & $4.42 *$ & $3.75^{* *}$ & 0.51 & 236.62 & 152.32 & $0.46+$ & 0.20 & $0.26 *$ & 0.019 * \\
\hline Line $\times$ Env & 87 & $1,142,066$ & $6.6^{* * *}$ & $5.5+$ & $0.75+$ & 203.4 & 134.7 & $0.3^{* * *}$ & 0.2 & $0.4^{* * *}$ & 0.01 \\
\hline Tester $\times$ Env & 6 & $7,541,546.2 †$ & 14.8 & $16.5+$ & 0.73 & $721.4^{* *}$ & $542.7^{* *}$ & $0.8^{* * *}$ & $0.81^{* * *}$ & $1.6+$ & $0.10+$ \\
\hline Line $\times$ Tester $\times$ Env & 174 & $1,487,490$ & 3 & 2.4 & 0.38 & 238 & 147.7 & 0.2 & 0.17 & 0.17 & $0.02 *$ \\
\hline Error & 359 & $1,565,284$ & 3.7 & 2.9 & 0.53 & 235.8 & 149.3 & 0.2 & 0.2 & 0.2 & 0.01 \\
\hline Repeatability & & 0.64 & 0.86 & 0.87 & 0.10 & 0.81 & 0.75 & 0.00 & 0.26 & 0.56 & 0.12 \\
\hline $\mathrm{CV}$ & & 27.8 & 3.4 & 3.1 & 37.99 & 8.9 & 13.9 & 15.9 & 15.6 & 16.2 & 12.22 \\
\hline
\end{tabular}

$* * * * * *,+$ significant at probability $<0.05,0.01,0.001$ and 0.0001 levels, respectively. 
Table 3. Estimates of genetic variance and standard error for each tester across four environments under Striga-infested and non-infested conditions.

\begin{tabular}{|c|c|c|c|c|c|c|c|}
\hline \multicolumn{4}{|c|}{ Striga-Infested Condition } & \multicolumn{4}{|c|}{ Striga-non-Infested Condition } \\
\hline Traits & T1 & T2 & T3 & Traits & T1 & T2 & T3 \\
\hline Grain yield $(\mathrm{kg} / \mathrm{ha})$ & $2.13^{* *} \pm 0.12$ & $1.68 * \pm 0.2$ & $1.97^{* *} \pm 0.1$ & Grain yield $(\mathrm{kg} / \mathrm{ha})$ & $1.77^{*} \pm 0.1$ & $1.67^{*} \pm 0.2$ & $0.89 \pm 0.1$ \\
\hline Silking (days) & $3.62+ \pm 0.4$ & $5.16+ \pm 0.2$ & $3.42+ \pm 0.3$ & Silking (days) & $3.15+ \pm 0.3$ & $4.53+ \pm 0.2$ & $3.08+ \pm 0.2$ \\
\hline Anthesis (days) & $3.15+ \pm 0.3$ & $5.77+ \pm 0.2$ & $3.07+ \pm 0.3$ & Anthesis (days) & $3.22+ \pm 0.2$ & $5.06+ \pm 0.2$ & $3.13+ \pm 0.2$ \\
\hline Anthesis-silking interval (days) & $1.05 \pm 0.1$ & $0.91 \pm 0.1$ & $0.94 \pm 0.1$ & Anthesis-silking interval (days) & $1.33 \pm 0.1$ & $1.23 \pm 0.1$ & $0.85 \pm 0.1$ \\
\hline Striga rating at $8 \mathrm{WAP}(1-9)$ & $1.46 \pm 0.1$ & $1.77^{*} \pm 0.1$ & $1.77^{*} \pm 0.1$ & Husk cover $(1-5)$ & $1.84^{*} \pm 0.1$ & $2.76^{* * *} \pm 0.1$ & $1.43 \pm 0.1$ \\
\hline Striga rating at $10 \mathrm{WAP}(1-9)$ & $1.46 \pm 0.2$ & $1.67^{*} \pm 0.2$ & $1.23 \pm 0.2$ & Plant aspect $(1-5)$ & $0.58 \pm 0.1$ & $2.08^{* *} \pm 0.1$ & $1.33 \pm 0.1$ \\
\hline Striga count at 8 WAP (no.) & $2.01^{* *} \pm 3.1$ & $1.54 \pm 2.8$ & $2.11^{* *} \pm 3.5$ & Ear height $(\mathrm{cm})$ & $4.13+ \pm 1.4$ & $2.42^{* *} \pm 1.7$ & $1.76^{*} \pm 1.7$ \\
\hline Striga count at 10 WAP (no.) & $1.56 \pm 4.5$ & $1.17 \pm 4.8$ & $1.32 \pm 5.2$ & Plant height $(\mathrm{cm})$ & $3.94+ \pm 1.8$ & $2.94+ \pm 2.1$ & $1.82 * \pm 2.1$ \\
\hline Plant height $(\mathrm{cm})$ & $1.97^{* *} \pm 2.3$ & $2.57^{* * *} \pm 1.9$ & $1.75^{*} \pm 1.8$ & Ear aspect (1-5) & $1.34 \pm 0.1$ & $1.65^{*} \pm 0.1$ & $1.39 \pm 0.1$ \\
\hline Ear aspect (1-5) & $1.66^{*} \pm 0.1$ & $2.57^{* * *} \pm 0.1$ & $1.62 * \pm 0.06$ & Ear per plant (no.) & $0.40 \pm 0.01$ & $2.0 * * \pm 0.02$ & $0.82 \pm 0.02$ \\
\hline Ear per plant (no.) & $1.28 \pm 0.01$ & $0.56 \pm 0.1$ & $2.50^{* * *} \pm 0.02$ & & & & \\
\hline
\end{tabular}

$* * * * * * *,+$ significant at probability $<0.05,0.01,0.001$ and 0.0001 levels, respectively. WAP $=$ weeks after planting. T1 $=$ Tolerant tester, $\mathrm{T} 2=$ Resistant tester and $\mathrm{T} 3=\mathrm{Susceptible} \mathrm{tester.}$ 


\subsection{Mean Performance of the Testcrosses}

Relative to the average grain yield under the non-infested condition, yield reduction under Striga infestation was $68 \%$ for the susceptible check (8338-1) and 45\% for the tolerant check (8425-8) (Table A3). Further, average testcross grain yield loss due to Striga damage was 20, 21 and 27\% for T1, T2 and T3, respectively. Under the Striga-infested condition, the number of testcrosses with $20 \%$ higher grain yields than the tolerant check was 29 for the tolerant tester, 27 for the resistant tester and 14 for the susceptible tester. The increase in testcross grain yield over the tolerant check ranged from 19 to $51 \%$ for the tolerant tester, 17 to $54 \%$ for the resistant tester and 0 to $44 \%$ for the susceptible tester. The resistant and tolerant testers had higher minimum, maximum and mean grain yields compared to the susceptible tester (Table 4). The resistant tester had the highest average testcross grain yield in testcrosses evaluated across environments. Of the top-ranking 15 testcrosses under Striga infestation, 8 to 10 were formed with the resistant tester (Table A3). Moreover, most hybrids formed from crosses of the resistant inbred lines with resistant and tolerant testers showed less Striga damage symptoms and supported fewer emerged parasites, while those formed from crosses of resistant inbred lines with the susceptible tester showed more Striga damage symptoms and supported many emerged Striga plants (Table 4).

Similarly, the highest mean grain yield under the Striga-non-infested condition was observed in crosses between resistant inbred lines and the resistant tester followed by testcrosses of the tolerant tester (Table 5). Mean grain yield of some testcrosses was significantly greater than that of the standard tolerant check hybrid across environments (Table A3). Three testcrosses involving the tolerant tester and nine testcrosses formed with the resistant tester had 20\% higher grain yields than the standard tolerant check under the Striga-non-infested condition. Testcrosses from the resistant and tolerant tester had the highest minimum, maximum and mean grain yields (Table 5). Amongst the 15 top-performing testcrosses, 11 involved the resistant tester. The average performance of testcrosses involving the three testers was similar for other traits. Lines L12, L3, L14, L1, L23, L25, L18, L6, L19, L17, L10, L28, L21, L16 and L29 showed better performance in crosses with the three testers across environments and can then be considered as good candidates to form single cross hybrids with high grain yields.

\subsection{Relative Ranking of Inbred Lines across Testers and Testers across Lines}

Significant coefficients of concordance were obtained for grain yield ranks of the lines $(\mathrm{W}=0.57)$ and testers $(W=0.44)$ under Striga-infested and for lines $(W=0.45)$ and testers $(W=0.50)$ under non-infested conditions. Significant coefficients of concordance of ranks of lines and testers were also obtained for most other agronomic traits under both infested and non-infested conditions (Table A4). The ranking based on BLUP values also showed similar coefficient of concordance with some discrepancies under infested and non-infested conditions (Table A5). Testcrosses involving the three testers showed significant concordance in ranks for grain yield and most other traits across environments under Striga infestation (Table 6). Amongst the testers, the tolerant and susceptible testers showed better rankings of the lines across environments under infestation. However, testcrosses of the susceptible tester showed below-average mean grain yields under Striga infestation resulting in discarding most resistant lines as undesirable parents (Tables A6-A8). On the other hand, testcrosses involving the three testers exhibited significant concordance in ranks for anthesis and silking days, plant height and ear height across environments under the Striga-non-infested condition. Only testcrosses of the tolerant tester had significant rank concordance for grain yield across environments, while those of the resistant tester had significant rank concordance for plant and ear aspect scores, husk cover and ears per plant under the non-infested condition (Table 6). 
Table 4. Means, maximum, minimum and standard error (Stderr) of agronomic traits for the testcrosses of yellow maize from three testers under the Striga-infested condition across four environments.

\begin{tabular}{|c|c|c|c|c|c|c|c|c|c|c|c|c|}
\hline \multirow[b]{2}{*}{ Variable } & \multicolumn{4}{|c|}{ Tolerant Tester (T1) } & \multicolumn{4}{|c|}{ Resistant Tester (T2) } & \multicolumn{4}{|c|}{ Susceptible Tester (T3) } \\
\hline & Min & Max & Mean & Stderr & Min & Max & Mean & Stderr & Min & $\operatorname{Max}$ & Mean & Stderr \\
\hline Grain yield (kg/ha) & 2823 & 4685 & 3705 & 89 & 2734 & 4960 & 3815 & 105 & 2032 & 4074 & 2931 & 79 \\
\hline Silking (days) & 56.1 & 61.1 & 58.5 & 0.2 & 56.4 & 62.6 & 59.7 & 0.3 & 54.1 & 59.8 & 57 & 0.3 \\
\hline Anthesis (days) & 54.3 & 58.8 & 56.5 & 0.2 & 54.8 & 60.8 & 57.6 & 0.3 & 52.8 & 57.8 & 55 & 0.2 \\
\hline Anthesis-silking interval (days) & 1.4 & 2.4 & 2 & 0.04 & 1.5 & 2.5 & 2.1 & 0.04 & 1.4 & 2.5 & 2 & 0.04 \\
\hline Striga rating at 8 WAP (1-9) & 2.5 & 4.3 & 3.1 & 0.1 & 2.4 & 4.6 & 3.3 & 0.1 & 3.1 & 4.9 & 4 & 0.1 \\
\hline Striga rating at 10 WAP (1-9) & 3.3 & 5.8 & 4.6 & 0.1 & 3.9 & 6.6 & 5.1 & 0.1 & 4.9 & 6.8 & 5.8 & 0.1 \\
\hline Striga count at 8 WAP (no.) & 11.3 & 56.1 & 31.9 & 2.2 & 11.4 & 44.4 & 27.6 & 1.8 & 17.5 & 79.1 & 37.5 & 2.5 \\
\hline Striga count at $10 \mathrm{WAP}$ (no.) & 24.1 & 75.6 & 49.3 & 2.8 & 23.3 & 76.8 & 46.6 & 2.6 & 29 & 88.4 & 55.4 & 3 \\
\hline Ear aspect (1-5) & 2.5 & 3.3 & 2.8 & 0.04 & 2.6 & 3.7 & 3 & 0.1 & 2.8 & 3.6 & 3.1 & 0.04 \\
\hline Plant height $(\mathrm{cm})$ & 138.6 & 176 & 158.9 & 1.6 & 153.3 & 183.1 & 165.8 & 1.5 & 143 & 166.4 & 155.7 & 1.2 \\
\hline Ear per plant (no.) & 0.8 & 1 & 0.9 & 0.01 & 0.7 & 1 & 0.9 & 0.01 & 0.6 & 1 & 0.8 & 0.02 \\
\hline
\end{tabular}

WAP = weeks after planting.

Table 5. Means, maximum, minimum and standard error (Stderr) of agronomic traits for the testcrosses of yellow maize from three testers under the Striga-non-infested condition across four environments.

\begin{tabular}{|c|c|c|c|c|c|c|c|c|c|c|c|c|}
\hline \multirow[b]{2}{*}{ Traits } & \multicolumn{4}{|c|}{ Tolerant Tester (T1) } & \multicolumn{4}{|c|}{ Resistant Tester (T2) } & \multicolumn{4}{|c|}{ Susceptible Tester (T3) } \\
\hline & Min & Max & Mean & Stderr & Min & $\operatorname{Max}$ & Mean & Stderr & Min & Max & Mean & Stderr \\
\hline Grain yield (kg/ha) & 3744.6 & 5514 & 4641.9 & 86.5 & 2926 & 5786 & 4803.4 & 115.8 & 3029 & 4738.4 & 4032.8 & 66.1 \\
\hline Silking (days) & 55.4 & 59.9 & 57.8 & 0.2 & 56 & 62.2 & 59 & 0.3 & 53.5 & 59.1 & 56.4 & 0.3 \\
\hline Anthesis (days) & 53.8 & 57.9 & 56 & 0.2 & 54.1 & 60.4 & 57.1 & 0.3 & 52.1 & 57.1 & 54.6 & 0.2 \\
\hline Anthesis-silking interval (days) & 1.0 & 2.38 & 1.87 & 0.05 & 1.13 & 2.88 & 1.94 & 0.05 & 1.38 & 2.38 & 1.89 & 0.04 \\
\hline Husk cover $(1-5)$ & 2.38 & 3.06 & 2.73 & 0.04 & 2.13 & 3.31 & 2.68 & 0.05 & 2.38 & 3.25 & 2.79 & 0.04 \\
\hline Plant aspect $(1-5)$ & 2.6 & 3.1 & 2.8 & 0.0 & 2.4 & 3.5 & 2.9 & 0.0 & 2.6 & 3.2 & 2.8 & 0 \\
\hline Ear height $(\mathrm{cm})$ & 71.9 & 102 & 87.2 & 1.4 & 77.6 & 103.8 & 89.1 & 1.3 & 77.5 & 100 & 86 & 1 \\
\hline Plant height $(\mathrm{cm})$ & 156.4 & 185 & 170.6 & 1.8 & 158.8 & 195 & 175.5 & 1.8 & 152 & 182.5 & 167.2 & 1.3 \\
\hline Ear aspect $(1-5)$ & 2.25 & 3.06 & 2.59 & 0.04 & 2.5 & 3.31 & 2.89 & 0.04 & 2.56 & 3.31 & 2.91 & 0.04 \\
\hline Ear per plant (no.) & 0.95 & 1.04 & 1.0 & 0.0 & 0.72 & 1.08 & 0.98 & 0.01 & 0.93 & 1.1 & 0.99 & 0.01 \\
\hline
\end{tabular}


Table 6. Kendall's coefficient of concordance (W) for ranks of yellow maize inbred lines by each tester across environments under Striga-infested and non-infested conditions.

\begin{tabular}{|c|c|c|c|c|c|c|c|}
\hline \multicolumn{4}{|c|}{ Striga-Infested Condition } & \multicolumn{4}{|c|}{ Striga-non-Infested Condition } \\
\hline Traits & T1 & T2 & T3 & Traits & T1 & T2 & T3 \\
\hline Grain yield (kg/ha) & $0.44^{* *}$ & $0.35 *$ & $0.40 * *$ & Grain yield (kg/ha) & $0.39 * *$ & 0.33 & 0.25 \\
\hline Anthesis (days) & $0.54+$ & $0.66+$ & $0.49^{* * *}$ & Anthesis (days) & $0.54+$ & $0.62+$ & $0.50 \dagger$ \\
\hline Anthesis-silking interval (days) & 0.23 & 0.24 & 0.24 & Anthesis-silking interval (days) & 0.30 & 0.26 & 0.24 \\
\hline Striga rating at 8 WAP (1-9) & 0.30 & $0.35 *$ & $0.35 *$ & Husk cover $(1-5)$ & $0.38 *$ & $0.51+$ & 0.34 \\
\hline Striga count at 10 WAP (no.) & $0.39 * *$ & 0.32 & 0.29 & Ear aspect (1-5) & 0.30 & $0.37 *$ & 0.34 \\
\hline Ear aspect $(1-5)$ & 0.33 & $0.46^{* * *}$ & 0.36 * & Plant height $(\mathrm{cm})$ & $0.58+$ & $0.50+$ & 0.36 * \\
\hline Plant height $(\mathrm{cm})$ & $0.46^{* * *}$ & $0.46^{* * *}$ & $0.37 *$ & Ear per plant (no.) & 0.16 & $0.42 * *$ & 0.18 \\
\hline Ear per plant (no.) & 0.26 & 0.16 & $0.39 * *$ & & & & \\
\hline
\end{tabular}

$*, * *, * * *,+$ significant at $p<0.05,0.01,0.001$ and 0.0001 levels, respectively. WAP $=$ weeks after planting. $\mathrm{T} 1=$ Tolerant

tester, T2 $=$ Resistant tester and T3 $=$ Susceptible tester.

\subsection{Combining Ability Estimates for Testers}

Under Striga infestation, the tolerant and resistant testers had significant and positive GCA effects for grain yield and negative GCA effects for Striga damage rating and Striga emergence count. In contrast, the susceptible tester had a significant and negative GCA effect for grain yield and positive GCA effect for Striga damage rating and Striga emergence count. The resistant tester had significant and positive GCA effects for anthesis and silking days as well as plant height under Striga infestation, while the susceptible tester had negative and significant GCA effects for these traits. The tolerant tester had a significant and desirable negative GCA effect for ear aspect, while the susceptible tester had a significant and undesirable GCA effect for this trait under Striga infestation. The resistant tester had significant and positive GCA effects for grain yield, anthesis and silking days, as well as plant height, while the susceptible tester had significant and negative GCA effects for these traits under the Striga-non-infested condition (Table 7). The GCA effect of the tolerant tester for grain yield under the non-infested condition, though positive, was not significant.

Table 7. Estimates of general combining ability (GCA) effects for three testers under Striga-infested and non-infested conditions.

\begin{tabular}{|c|c|c|c|c|c|c|c|}
\hline \multicolumn{4}{|c|}{ Striga-Infested Condition } & \multicolumn{4}{|c|}{ Striga-non-Infested Condition } \\
\hline Traits & T1 & T2 & T3 & Traits & T1 & T2 & T3 \\
\hline Grain yield (kg/ha) & $221.4^{*}$ & $331.3^{* *}$ & $-552.7^{* * *}$ & Grain yield (kg/ha) & 149.2 & 310.7 * & $-459.8^{* *}$ \\
\hline Silking (days) & 0.11 & $1.3^{* * *}$ & $-1.42+$ & Silking (days) & 0.07 & $1.24^{* * *}$ & $-1.31^{* * *}$ \\
\hline Anthesis (days) & 0.15 & $1.19^{* * *}$ & $-1.34 * * *$ & Anthesis (days) & 0.1 & $1.20^{* * *}$ & $-1.3^{* * *}$ \\
\hline Anthesis-silking interval (days) & -0.05 & 0.09 & -0.04 & Anthesis-silking interval (days) & -0.03 & 0.04 & -0.01 \\
\hline Striga rating at 8 WAP (1-9) & $-0.39 *$ & -0.15 & $0.55^{* *}$ & Husk cover $(1-5)$ & -0.13 * & $0.11 *$ & 0.02 \\
\hline Strig $a$ rating at 10 WAP (1-9) & $-0.6^{* *}$ & -0.07 & $0.66^{* *}$ & Plant aspect $(1-5)$ & -0.01 & 0.02 & -0.01 \\
\hline Striga count at 8 WAP (no.) & -0.46 & $-4.74 *$ & $5.19 *$ & Ear height $(\mathrm{cm})$ & -0.3 & 1.79 & -1.46 \\
\hline Striga count at $10 \mathrm{WAP}$ (no.) & -1.14 & -3.87 & 5 & Ear aspect $(1-5)$ & $-0.2^{* *}$ & 0.1 & 0.11 \\
\hline Ear aspect $(1-5)$ & $-0.18^{*}$ & 0.03 & 0.14 * & Plant height $(\mathrm{cm})$ & -0.56 & $4.56^{* *}$ & $-3.98 *$ \\
\hline Plant height $(\mathrm{cm})$ & -1.20 & $5.67^{* * *}$ & $-4.47^{* *}$ & Ear per plant (no.) & 0.007 & -0.01 & 0.002 \\
\hline Ear per plant (no.) & 0.026 & 0.034 & -0.061 & & & & \\
\hline
\end{tabular}

$*, * *, * * *,+$ significant at $p<0.05,0.01,0.001$ and 0.0001 levels, respectively. WAP $=$ weeks after planting. T1 $=$ Tolerant tester, $\mathrm{T} 2=$ Resistant tester and T3 $=$ Susceptible tester.

\subsection{Principal Components (PC) for Agronomic Traits for Each Tester}

The principal component analysis was computed to determine the combination of traits that significantly contributed to the performance of testcrosses of the three testers. The first two principal component axes (PC1 and PC2) together accounted for $64 \%$ of the total variation among testcrosses under Striga infestation (Table 8). The PC1 axis scores of the 90 testcrosses were significantly associated with earlier anthesis and silking, shorter anthesis and silking interval, increases in Striga damage symptoms and Striga count, less number of ears per plant and grain yield. Further, all traits, except 
Striga damage rating at $10 \mathrm{WAP}$, significantly contributed to the PC2 axis score of testcrosses under Striga infestations. Under the Striga-non-infested condition, PC1 and PC2 jointly explained $53 \%$ of the total variation among 90 testcrosses (Table 8). The PC1 axis scores of the 90 testcrosses were associated with significant increases in all traits except for husk cover, plant aspect and ears per plant. Testcrosses had PC2 axis scores that were significantly correlated with delays in anthesis and silking, undesirable husk cover, plant aspect and ear aspect scores, lower ear placement, shorter plants, reduced number of ears per plant and grain yield (Table 8). It is interesting to note that grain yield showed significant negative associations with PC1 and PC2 axes scores of testcrosses under Striga infestation but had a significant positive correlation with PC1 axis scores and negative correlation with PC2 axis scores of testcrosses under the non-infested condition (Table 8). As shown in Figure 1, most of the testcrosses involving the tolerant (T1) and resistant (T2) testers had negative PC1 axis scores, whereas most testcrosses of the susceptible (T3) tester had positive PC1 axis scores. These results indicated that the testcrosses involving T1 and T2 combined high grain yields with other desirable traits recorded under infestation. Further, many testcrosses of T1 and T2 had positive PC1 axis scores under the non-infested condition, while many of the T3 testcrosses had negative PC1 axis scores (Figure 1). Once again, these results indicated that testcrosses of both $\mathrm{T} 1$ and $\mathrm{T} 2$ combined high grain yields with other desirable agronomic properties, whereas those of T3 showed low grain yields with undesirable agronomic traits even under the non-infested condition.
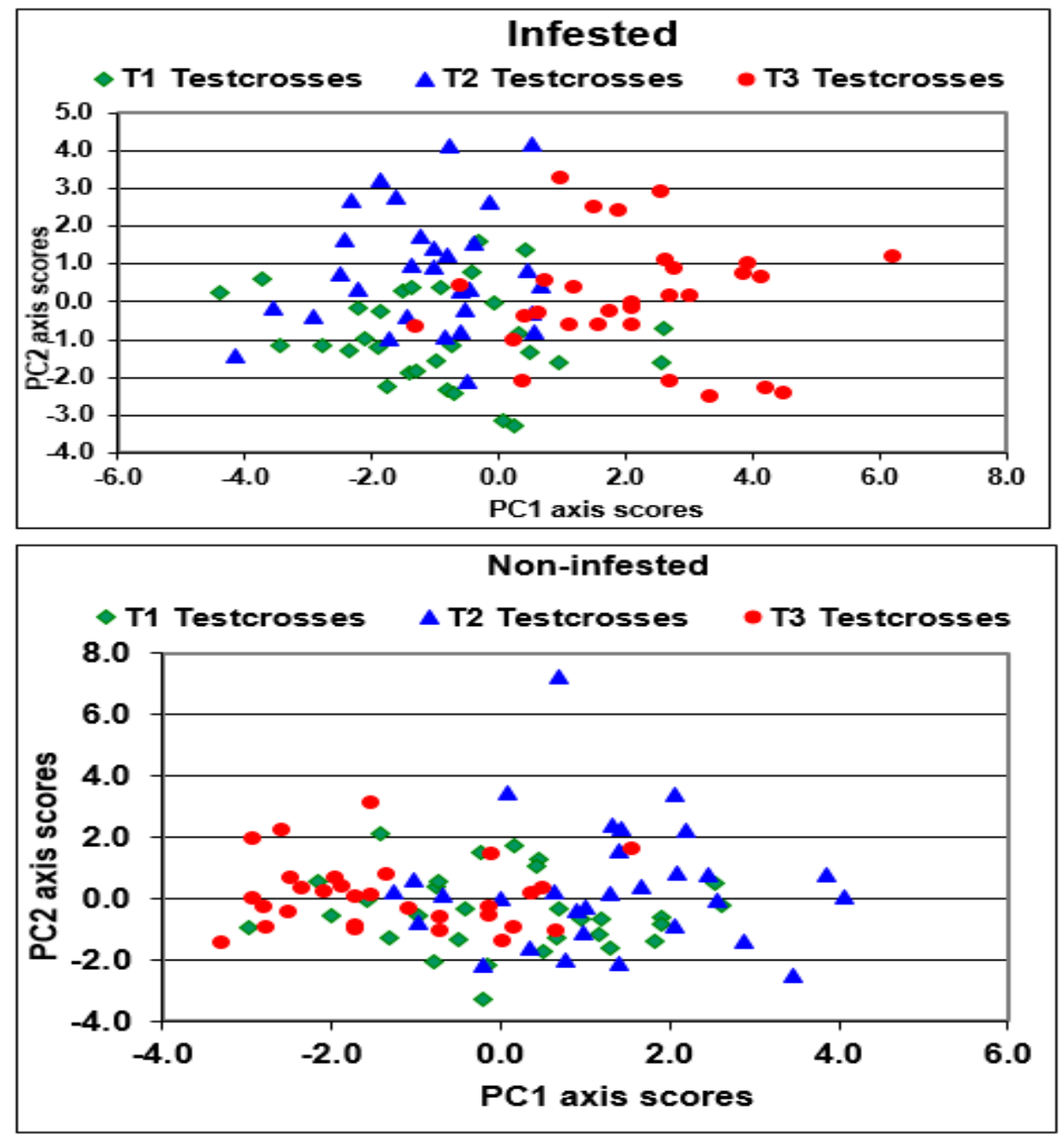

Figure 1. Scatter plot of testcrosses involving three testers evaluated under Striga-infested and non-infested conditions at four test environments in Nigeria. Where T1 = Tolerant tester, T2 = Resistant tester and $\mathrm{T} 3=$ Susceptible tester. 
Table 8. Eigenvectors of the first two principal component axes (PC1 and PC2) for yellow maize testcrosses involving the testers evaluated under Striga-infested and non-infested conditions.

\begin{tabular}{|c|c|c|c|c|c|}
\hline \multirow[b]{2}{*}{ Traits } & \multicolumn{2}{|c|}{ Infested } & \multirow[b]{2}{*}{ Traits } & \multicolumn{2}{|c|}{ Non-Infested } \\
\hline & PC1 & PC2 & & PC1 & PC2 \\
\hline Grain yield (kg/ha) & $-0.37+$ & $-0.23^{* * *}$ & Grain yield (kg/ha) & $0.32+$ & $-0.36+$ \\
\hline Silking (days) & $-0.30+$ & $0.43+$ & Silking (days) & $0.46+$ & $0.33+$ \\
\hline Anthesis (days) & $-0.29+$ & $0.41+$ & Anthesis (days) & $0.46+$ & $0.30+$ \\
\hline Anthesis-silking interval (days) & $-0.11 *$ & $0.33+$ & Anthesis-silking interval (days) & $0.15 *$ & $0.26+$ \\
\hline Striga rating at 8 WAP (1-9) & $0.35+$ & $-0.16^{*}$ & Husk cover $(1-5)$ & $-0.20 * *$ & $0.31+$ \\
\hline Striga rating at $10 \mathrm{WAP}(1-9)$ & $0.31+$ & -0.12 & Plant height $(\mathrm{cm})$ & $0.46+$ & $-0.23+$ \\
\hline Striga count at $8 \mathrm{WAP}$ (no.) & $0.38+$ & $0.16^{*}$ & Ear height $(\mathrm{cm})$ & $0.44+$ & $-0.19 * *$ \\
\hline Striga count at $10 \mathrm{WAP}$ (no.) & $0.38+$ & $0.21 * *$ & Plant aspect (1-5) & 0.02 & $0.36+$ \\
\hline Plant height (cm) & $-0.25+$ & $0.18^{* *}$ & Ear aspect $(1-5)$ & -0.02 & $0.38+$ \\
\hline Ear aspect (1-5) & $0.21+$ & $0.45+$ & Ear per plant (no.) & -0.10 & $-0.38+$ \\
\hline Ear per plant (no.) & $-0.27+$ & $-0.37+$ & Variance & 0.29 & 0.24 \\
\hline Variance & 0.41 & 0.23 & & & \\
\hline
\end{tabular}

$*, * *, * * *,+$ significant correlation with axis scores at $p<0.05,0.01,0.001$ and 0.0001 levels, respectively. WAP $=$ weeks after planting.

\section{Discussion}

Considerable progress has been made in breeding maize hybrids that are resistant and tolerant to Striga hermonthica in West and Central Africa (WCA) $[17,18,47,48]$. An understanding of the relative value of different types of testers in eliciting genetic differences among new lines is important in resistance hybrid breeding programs [25-27]. In the present study, the significant GCA effects of both lines and testers for most traits as well as the significant SCA effects for many traits under Striga-infested and non-infested conditions imply that both additive and non-additive gene effects were important in controlling the measured traits. The fact that the average GCA effect of the lines was 1.5 times greater than their SCA effect and that of the testers was 32.4 times greater than the SCA effects, the additive gene action of the testers was more important in controlling the overall performance of testcrosses. Studies have shown that genetic gain from selection with inbred testers is mainly associated with an additive gene effect rather than non-additive effects [49,50]. Karaya et al. [51] reported significant GCA effects of Striga rating and Striga count at 8,10 and 12 WAP. Our study showed that the genetic variation for resistance to $S$. hermontica among lines was mostly controlled by the additive type of gene action. In line with this result, additive genetic effects were more important in controlling host plant damage syndrome rating and grain yield, while a non-additive gene action was involved in controlling the number of emerged Striga plants under Striga infestation [18,52,53]. As the relative value of the yellow testers differed markedly with their resistance reactions to Striga hermonthica in our study, the deployment of appropriate testers has a good prospect to further increase genetic gains in resistance hybrid development programs targeting at increasing maize yield in Striga-endemic areas of WCA.

Several factors including gene frequency of favorable alleles, average testcrosses performance, the magnitude of variance estimates and GCA effects have been considered useful to choose appropriate testers in hybrid breeding $[33,34,54]$. In our study, testcrosses of the tolerant tester had the largest genetic variance for grain yield under Striga-infested and non-infested conditions, possibly because the tester carried favorable alleles at an intermediate to a higher frequency for resistance to the parasite that induced the largest genetic differences among testcrosses for grain yield and most other traits under the Striga-infested condition. In contrast, the susceptible tester had a moderate variance estimate for grain yield, and many of its testcrosses performed poorly across environments. These results contradict the idea of Rawlings and Thompson [29] and Hallauer and Lopez-Perez [55], who reported that a low-performing tester with a low frequency of favorable alleles at important loci would be more effective in differentiating the potential value of inbred lines. A tester with the greatest testcross genetic variance could discriminate groups of inbred lines and identify the best lines among testcrosses 
in trials [34]. The tolerant tester could thus be regarded as a suitable tester for use in breeding for Striga-resistant hybrids. However, Keller [56] suggested the use of more than one tester for an accurate assessment of the ranking of lines in crosses with testers and to obtain better variance estimates among testcrosses involving each tester. Consequently, the resistant tester may also be used as an alternative tester to evaluate the inbred lines for Striga resistance breeding.

The selection of an appropriate tester should not rely solely on the magnitude of the genetic variance but also ranges and mean values of traits under study. Lopez-Perez [54] found that larger genetic variance estimates of testcrosses were associated with a broader range in mean values for all the measured traits. In our study, testcrosses of the tolerant tester had the largest genetic variance for grain yield but showed the lowest range for testcross mean grain yields. In contrast, testcrosses of the resistant tester exhibited the greatest range for mean grain yields but had the lowest genetic variance, indicating that this tester also provided greater opportunity to discriminate among the Striga-resistant lines. Furthermore, most hybrids formed from crosses of resistant inbred lines with the resistant and tolerant testers showed less Striga damage symptoms and supported fewer emerged parasites than the susceptible tester. These results coupled with the results from orthogonal contrasts clearly showed that the tolerant and resistant testers had a higher frequency of favorable alleles for resistance to $S$. hermonthica in comparison to the susceptible tester that allowed them to form high-yielding testcrosses with other desirable agronomic features under both infested and non-infested conditions. It appears that the susceptible tester had dominant unfavorable alleles for resistance to S. hermonthica at many loci that adversely affected the performance of hybrids, particularly under the infested condition. According to Tandon and Batra [57], most productive lines tend to make high-yielding crosses, whereas poor inbred lines formed crosses with poor yield performance. In a breeding program focusing on developing viable hybrids for commercialization, the best tester is the one that is high yielding, has good discriminating ability among lines and forms productive hybrid combinations. Therefore, the tolerant and resistant testers can be considered suitable for evaluating and effectively selecting promising parental lines in resistance hybrid breeding programs.

Breeders are mainly interested in selecting inbred lines that are high yielding as lines and in testcrosses with other lines. The tolerant and resistant testers with positive GCA effects for grain yield under Striga-infested and non-infested conditions can then be regarded as suitable testers. The tolerant and resistant testers with large GCA effects for grain yield seem to have the highest frequency of favorable alleles for use as a good tester to characterize the yield potential and Striga resistance-related traits of new yellow maize inbred lines under Striga infestation. This is consistent with studies of Fato et al. [40], who found that the resistant tester was superior to the susceptible tester in identifying maize inbred lines with high levels of resistance to downy mildew and high yield potential in hybrids.

Testers with a high frequency of favorable alleles can also be used to identify the best lines with the highest specific combining ability [39]. The tolerant tester identified two lines forming testcrosses and the resistant tester identified four lines forming testcrosses showing significant and positive SCA effects for grain yield in the present study, whereas the susceptible tester did not identify any line in testcrosses having a significant and positive SCA effect under the two growing conditions (Table A9a,b). Therefore, the tolerant and resistant testers that identified lines with desirable SCA effects can serve as suitable testers to evaluate inbred lines in Striga resistance breeding programs.

A suitable tester should provide a correct ranking of the relative merit of lines under test [50]. The tolerant and resistant testers ranked the yellow endosperm maize inbred lines better for Striga damage rating and Striga count in the present study. These testers ranked the performance of inbred lines better across environments, which is important in identifying good testcrosses for further testing and direct use or as potential female parents to develop three-way cross hybrids. Further, the tolerant and resistant testers consistently identified most of the inbred lines that formed the top 15 testcrosses identified under the two growing conditions in the present study, although the relative ranks were not identical. In contrast, only one testcross of the susceptible tester was found among the top 15 testcrosses identified under infestation and no testcross of this tester ranked in the top 15 testcrosses 
under the non-infested condition. As testcrosses of the susceptible tester that produced low grain yields showed severe Striga damage symptoms and supported more emerged Striga plants, many useful inbred lines with high yield potential under infestation could be discarded. Genter [58] concluded that during a testcross evaluation, a gene from a tester parent might mask and interact with the inbred line under test that may affect the accuracy of determining the genotype of the line under study. These results confirmed the effectiveness of the tolerant and resistant testers for evaluating the yellow endosperm-resistant maize inbred lines, consistent with the conclusions of Rawlings and Thompson [29].

Lopez-Perez [54] indicated that testers should not be selected based on their yielding ability alone but also based on other important agronomic traits. In our study, the results of principal component analyses showed that testcrosses involving all three testers combined high grain yields with favorable performance in other traits notwithstanding the observed difference of the three testers having different sets of traits that contributed significantly to PC1 and PC2 axes scores. Genter [58] recommended that a hybrid breeding program must focus on the development of inbred lines with simultaneous selection for many traits which determine the net worth of the lines. Further, Hallauer [50] suggested that effective selection for desirable agronomic traits and resistance to diseases and insects in crosses with an inbred tester can enhance the development of new superior lines that are useful in combination with other elite lines. Both the tolerant and resistant testers showing sets of key traits contributing significantly to desirable performance in testcrosses are thus suitable for screening Striga-resistant yellow endosperm maize inbred lines in resistance hybrid breeding programs.

In conclusion, this study was conducted to determine the effectiveness of three yellow endosperm maize inbred testers with diverse resistance reactions to $S$. hermonthica for selecting lines with a high expression of resistance to the parasite in hybrid combinations. Our study clearly demonstrated that the tolerant and resistant testers that combined positive GCA effects with greater genetic variances, broader range in mean grain yields among testcrosses and consistent ranking of testcross grain yields across environments under both infested and non-infested conditions can be considered as suitable testers for resistance hybrid breeding targeting Striga-affected areas. In maize breeding programs that do not have established testers, the tolerant and resistant lines may serve as suitable testers to separate yellow endosperm maize inbred lines into heterotic groups to optimize heterosis in hybrids. The two testers can also be used as sources of favorable alleles to create new allelic combinations with elite lines belonging to established heterotic groups to generate diverse parental lines that can be used as parents to develop new superior resistant hybrids.

Author Contributions: Conceptualization, A.M.; data collection and experimentation D.Z. and A.M.; formal analysis, D.Z. and A.M.; writing—original draft preparation, D.Z.; writing-review and editing, A.M., V.A., W.M., S.M., M.G. All authors have read and agreed to the published version of the manuscript.

Funding: This study was part of PhD research of the first author, funded by African Union and the Bill and Malinda Gates Foundation, through the framework of Pan African University and the Stress Tolerant Maize for Africa (STMA), respectively.

Acknowledgments: We gratefully acknowledge the support of the technical staff of the Maize Improvement Programme of IITA in field operations.

Conflicts of Interest: The authors declare that we have no conflict of interest. 


\section{Appendix A}

Table A1. Description of Striga-resistant inbred lines and the three testers used in the experiment.

\begin{tabular}{|c|c|c|}
\hline Lines & Name & Pedigree \\
\hline L1 & TZISTR1224 & (ACR97SYN-Y-S1-79-B×4/ACR97TZLComp1-YS155-4-1-3-B×4)-9-1-BB-B \\
\hline L2 & TZISTR1215 & (ACR97SYN-Y-S1-79-B×4/ACR97TZLComp1-YS155-4-1-3-B×4)-62-1-B-B \\
\hline L3 & TZISTR1220 & (ACR97SYN-Y-S1-24-B×4/ACR97TZLComp1-YS155-4-1-3-B×4)-13-1-BB-B \\
\hline L4 & TZISTR1222 & (ACR97SYN-Y-S1-24-B×4/ACR97TZLComp1-YS155-4-1-3-B×4)-42-1-BB-B \\
\hline L5 & TZISTR1223 & (ACR97SYN-Y-S1-24-B×4/ACR97TZLComp1-YS155-4-1-3-B×4)-44-1-BB-B \\
\hline L6 & TZISTR1225 & (ACR97SYN-Y-S1-79-B×4/ACR97TZLComp1-YS155-4-1-3-B×4)-14-1-BB-B \\
\hline L7 & TZISTR1226 & (ACR97SYN-Y-S1-79-B×4/ACR97TZLComp1-YS155-4-1-3-B×4)-19-1-BB-B \\
\hline L8 & TZISTR1227 & (ACR97SYN-Y-S1-79-B×4/ACR97TZLComp1-YS155-4-1-3-B×4)-24-1-BB-B \\
\hline L9 & TZISTR1228 & (ACR97SYN-Y-S1-79-B×4/ACR97TZLComp1-YS155-4-1-3-B×4)-26-1-BB-B \\
\hline L10 & TZISTR1230 & (ACR97SYN-Y-S1-79-B×4/ACR97TZLComp1-YS155-4-1-3-B×4)-31-1-BB-B \\
\hline L11 & TZISTR1231 & (ACR97SYN-Y-S1-79-B×4/ACR97TZLComp1-YS155-4-1-3-B×4)-46-1-BB-B \\
\hline L12 & TZISTR1232 & (ACR97SYN-Y-S1-79-B×4/ACR97TZLComp1-YS155-4-1-3-B×4)-50-1-BB-B \\
\hline L13 & TZISTR1235 & (ACR97SYN-Y-S1-79-B×4/ACR97TZLComp1-YS155-4-1-3-B×4)-66-1-BB-B \\
\hline L18 & TZISTR1214 & (ACR97SYN-Y-S1-79-B×4/ACR97TZLComp1-YS155-4-1-3-B×4)-61-1-B-B \\
\hline L22 & TZISTR1233 & (ACR97SYN-Y-S1-79-B×4/ACR97TZLComp1-YS155-4-1-3-B×4)-55-1-BB-B \\
\hline L14 & TZISTR1236 & (ACR97TZLComp1-YS155-4-1-3-B×4/ACR97SYN-Y-S1-76-B×4)-1-1-BB-B \\
\hline L15 & TZISTR1237 & (ACR97TZLComp1-YS155-4-1-3-B×4/ACR97SYN-Y-S1-76-B×4)-9-1-BB-B \\
\hline L16 & TZISTR1238 & (ACR97TZLComp1-YS155-4-1-3-B×4/ACR97SYN-Y-S1-76-B×4)-10-1-BB-B \\
\hline L17 & TZISTR1211 & (ACR97TZLComp1-YS155-4-1-3-B×4/ACR97SYN-Y-S1-76-B×4)-20-1-B-B \\
\hline L19 & TZISTR1216 & (ACR97TZLComp1-YS155-4-1-3-B×4/ACR97SYN-Y-S1-76-B×4)-21-1-BB-B \\
\hline L20 & TZISTR1217 & (ACR97TZLComp1-YS155-4-1-3-B×4/ACR97SYN-Y-S1-76-B×4)-32-1-BB-B \\
\hline L21 & TZISTR1218 & (ACR97TZLComp1-YS155-4-1-3-B×4/ACR97SYN-Y-S1-76-B×4)-44-1-BB-B \\
\hline $\mathrm{L} 23$ & TZSTRI109 & ACR97SYN-Y-S1-79-B-B-B \\
\hline L24 & TZSTRI110 & ACR97SYN-Y-S1-24-B-B-B \\
\hline L25 & TZSTRI112 & TZE COMP5-25-1-1-3-\#-2-B-B-B \\
\hline L26 & TZSTRI113 & TZEComp.5-Y-20-1-1-3-\#-2-B-B-B-B \\
\hline L27 & TZSTRI114 & TZECOMP5-Y-C7-S3-55-B-B-B \\
\hline $\mathrm{L} 28$ & TZISTR1028 & ACR97TZL-CCOMP1-Y-S3-33-6-B×8 \\
\hline L29 & TZISTR1029 & ACR97TZL-CCOMP1-Y-S3-12-2-B×8 \\
\hline L30 & TZISTR1030 & ACR97TZL-CCOMP1-Y-S3-6-1-B×9 \\
\hline \multicolumn{3}{|r|}{ 1 } \\
\hline $\mathrm{T} 1$ & TZISTR1207 (T) & $9450 \times C M 116 \times 9450)-3-3-1-2-1-B \times 8$ \\
\hline $\mathrm{T} 2$ & TZSTRI106 (R) & Z.diplo.BC4-376-1-1-\#-3-1-B-2-B×8 \\
\hline T3 & TZISTR1033 (S) & $9450 \times \mathrm{KI} 21-3-2-2-2-1-\mathrm{B} \times 8$ \\
\hline \multicolumn{3}{|r|}{ Standard hybrid checks } \\
\hline 1 & $8425-8$ & Tolerant \\
\hline 2 & $8338-1$ & Susceptible \\
\hline
\end{tabular}


Table A2. Mean squares of testcrosses for each tester across four environments under Striga-infested non-infested conditions.

\begin{tabular}{|c|c|c|c|c|c|c|c|c|c|c|c|}
\hline \multicolumn{7}{|c|}{ Striga-Infested Condition } & \multicolumn{5}{|c|}{ Striga-non-Infested Condition } \\
\hline Traits & Testers & Environment & Testcross & Mean & $\mathrm{CV}$ & Traits & Testers & Environment & Testcross & Mean & $\mathrm{CV}$ \\
\hline \multirow[t]{3}{*}{ DYSK } & T1 & $841.4+$ & $7.2+$ & 58.5 & 2.4 & DYSK & T1 & $903.5+$ & $6.0+$ & 57.8 & 2.4 \\
\hline & $\mathrm{T} 2$ & $824.9+$ & $9.2+$ & 59.6 & 2.2 & & $\mathrm{~T} 2$ & $898.5+$ & $8.4+$ & 59.0 & 2.3 \\
\hline & $\mathrm{T} 3$ & $1079.4+$ & $7.7+$ & 57.0 & 2.6 & & $\mathrm{~T} 3$ & $1174.7+$ & $7.7+$ & 56.4 & 2.8 \\
\hline \multirow[t]{3}{*}{ DYSP } & $\mathrm{T} 1$ & $875.9+$ & $5.8+$ & 56.5 & 2.4 & DYSP & $\mathrm{T} 1$ & $962.5+$ & $5.0+$ & 55.9 & 2.2 \\
\hline & $\mathrm{T} 2$ & $805.3+$ & $8.76+$ & 57.6 & 2.1 & & $\mathrm{~T} 2$ & $913.3+$ & $7.6+$ & 57.0 & 2.1 \\
\hline & $\mathrm{T} 3$ & $1120.9+$ & $6.3+$ & 55.0 & 2.6 & & T3 & $1241.4+$ & $6.7+$ & 54.5 & 2.7 \\
\hline \multirow[t]{3}{*}{ ASI } & $\mathrm{T} 1$ & $1.0 * *$ & 0.21 & 1.93 & 23.2 & ASI & T1 & $1.99+$ & 0.3 & 1.87 & 25.7 \\
\hline & $\mathrm{T} 2$ & 0.3 & 0.22 & 2.08 & 23.9 & & T2 & $2.1^{* * *}$ & 0.4 & 1.93 & 27.6 \\
\hline & T3 & $2.0+$ & 0.23 & 1.94 & 25.6 & & T3 & $4.5 \dagger$ & 0.2 & 1.89 & 26.0 \\
\hline \multirow[t]{3}{*}{ PL HT } & $\mathrm{T} 1$ & $13,309.2+$ & $302.9^{* *}$ & 158.9 & 7.8 & PL HT & $\mathrm{T} 1$ & $11,702.9+$ & $394.9+$ & 170.6 & 5.9 \\
\hline & $\mathrm{T} 2$ & $20,825.3+$ & $264.9 * * *$ & 165.8 & 6.1 & & $\mathrm{~T} 2$ & $18,456.6+$ & $390.0+$ & 175.4 & 6.6 \\
\hline & T3 & $13,835.6+$ & $166.6^{*}$ & 155.7 & 6.3 & & T3 & $11,183.3+$ & $194.6^{*}$ & 167.2 & 6.2 \\
\hline \multirow{3}{*}{ STRRAT1 } & $\mathrm{T} 1$ & $3.8 * * *$ & 0.8 & 3.1 & 23.7 & EHT & T1 & $13,011.9+$ & $242.8+$ & 87.2 & 8.8 \\
\hline & T2 & $11.1+$ & 0.9 * & 3.3 & 21.7 & & $\mathrm{~T} 2$ & $17,085.1+$ & $208.0 * * *$ & 89.1 & 10.4 \\
\hline & $\mathrm{T} 3$ & $32.0+$ & $0.82 *$ & 4.0 & 16.8 & & $\mathrm{~T} 3$ & $10,648.8+$ & $123.6^{*}$ & 86.0 & 9.7 \\
\hline \multirow{3}{*}{ STRRAT2 } & $\mathrm{T} 1$ & $14.6+$ & 1.3 & 4.6 & 20.9 & HUSK & $\mathrm{T} 1$ & $7.3+$ & $0.2 *$ & 2.5 & 12.8 \\
\hline & T2 & $46.8+$ & 1.7 * & 5.1 & 20.0 & & T2 & $4.7 \dagger$ & $0.4^{* * *}$ & 2.8 & 13.8 \\
\hline & $\mathrm{T} 3$ & $56.8+$ & 1.1 & 5.8 & 16.5 & & T3 & $7.8+$ & 0.15 & 2.7 & 11.8 \\
\hline \multirow[t]{3}{*}{ STRCO1 } & $\mathrm{T} 1$ & $19,346.1+$ & $561.7^{* *}$ & 31.9 & 52.5 & PASP & $\mathrm{T} 1$ & $9.0 \dagger$ & 0.06 & 2.8 & 11.0 \\
\hline & T2 & $18,533.6+$ & 372.7 & 27.6 & 56.4 & & $\mathrm{~T} 2$ & $5.2+$ & $0.23 * *$ & 2.9 & 11.5 \\
\hline & T3 & $26,704.6+$ & $777.5^{* *}$ & 37.5 & 51.1 & & T3 & $8.3+$ & 0.11 & 2.8 & 9.9 \\
\hline \multirow{3}{*}{ STRCO2 } & $\mathrm{T} 1$ & $67,040.7+$ & 926.9 & 49.3 & 49.4 & EASP & $\mathrm{T} 1$ & $2.9+$ & 0.16 & 2.6 & 13.5 \\
\hline & $\mathrm{T} 2$ & $72,326.6+$ & 791.2 & 46.5 & 55.9 & & $\mathrm{~T} 2$ & $5.5+$ & $0.18 *$ & 2.9 & 11.6 \\
\hline & T3 & $93,144.5+$ & 1078.5 & 55.4 & 51.6 & & T3 & $7.1 \dagger$ & 0.16 & 2.9 & 11.7 \\
\hline \multirow[t]{3}{*}{ EASP } & $\mathrm{T} 1$ & $3.4+$ & $0.15^{*}$ & 2.8 & 10.7 & EPP & $\mathrm{T} 1$ & $0.02 *$ & 0.002 & 1.00 & 7.9 \\
\hline & $\mathrm{T} 2$ & $4.8+$ & $0.3^{* * *}$ & 3.0 & 11.3 & & $\mathrm{~T} 2$ & $0.17+$ & $0.02 * *$ & 0.98 & 11.3 \\
\hline & T3 & $8.3+$ & $0.16^{*}$ & 3.1 & 10.1 & & T3 & $0.05^{* * *}$ & 0.01 & 0.99 & 8.3 \\
\hline \multirow[t]{3}{*}{ EPP } & $\mathrm{T} 1$ & $0.19+$ & 0.01 & 0.94 & 8.4 & YLD & $\mathrm{T} 1$ & $33,821,388.6+$ & $898,294.7^{*}$ & 4641.9 & 15.3 \\
\hline & $\mathrm{T} 2$ & 0.21 & 0.08 & 0.95 & 39.3 & & $\mathrm{~T} 2$ & $82,146,365.9+$ & $1,608,539.2 *$ & 4803.4 & 20.5 \\
\hline & $\mathrm{T} 3$ & $0.9+$ & $0.03 * * *$ & 0.85 & 13.1 & & T3 & $51,251,103.6+$ & $524,149.6$ & 4032.8 & 19.0 \\
\hline \multirow[t]{3}{*}{ YLD } & $\mathrm{T} 1$ & $54,630,065.1+$ & $945,426.1$ ** & 3704.9 & 18.0 & & & & & & \\
\hline & $\mathrm{T} 2$ & $95,250,316.6+$ & $1,313,011$ * & 3814.8 & 23.2 & & & & & & \\
\hline & $\mathrm{T} 3$ & $88,841,722.3+$ & $752,937.4$ ** & 2930.8 & 21.1 & & & & & & \\
\hline
\end{tabular}

$*, * *, * * *,+$ significant at $p<0.05,0.01,0.001$ and 0.0001 levels, respectively. ASI $=$ anthesis-silking interval, DYSK $=$ days to $50 \%$ silking, DYPOL $=$ days to $50 \%$ anthesis, PLHT $=$ plant height $(\mathrm{cm})$, STRRAT1 and STRRAT2 = Striga damage rating (rating at a scale of 1-9) at 8 and 10 WAP, respectively, STRCO1 and STRCO2 = Striga emergence count at 8 and 10 WAP, respectively, EASP = ear aspect (rating at a scale of 1-5), PASP = qualitative observation of plant ideotype rated using a scale of 1 to 5 , HUSK = the degree of the husk covering the tip of the ear using a scale of 1 to $5, \mathrm{EPP}=$ ears per plant and $\mathrm{YLD}=$ grain yield $(\mathrm{kg} / \mathrm{ha})$. 
Table A3. Agronomic performance of testcrosses for some selected traits under artificial Striga infestation.

\begin{tabular}{|c|c|c|c|c|c|c|c|c|c|c|c|}
\hline Testcrosses & YLDIN & YLDUN & RED (\%) & DYSK & DYSP & EASP & EPP & $\mathrm{CO} 1$ & $\mathrm{CO} 2$ & RAT1 & RRAT2 \\
\hline $\mathrm{L} 1 \times \mathrm{T} 1$ & 4015.7 & 4535.8 & 11.5 & 59.1 & 57.1 & 2.6 & 1.0 & 15.1 & 31.1 & 2.5 & 3.9 \\
\hline $\mathrm{L} 2 \times \mathrm{T} 1$ & 3228.2 & 4453.8 & 27.5 & 60.0 & 58.1 & 2.8 & 0.9 & 27.0 & 37.5 & 3.6 & 4.0 \\
\hline $\mathrm{L} 3 \times \mathrm{T} 1$ & 4610.3 & 5033.8 & 8.4 & 58.6 & 56.9 & 2.6 & 0.9 & 17.9 & 26.3 & 2.8 & 4.5 \\
\hline $\mathrm{L} 4 \times \mathrm{T} 1$ & 3280.5 & 3891.1 & 15.7 & 59.5 & 57.4 & 2.9 & 0.9 & 44.8 & 62.4 & 3.3 & 4.6 \\
\hline $\mathrm{L} 5 \times \mathrm{T} 1$ & 3355.8 & 4798.6 & 30.1 & 60.5 & 58.4 & 3.1 & 0.9 & 34.5 & 52.8 & 3.8 & 5.6 \\
\hline $\mathrm{L} 6 \times \mathrm{T} 1$ & 3714.4 & 4387.1 & 15.3 & 59.3 & 57.5 & 2.7 & 1.0 & 39.6 & 54.9 & 2.5 & 3.9 \\
\hline $\mathrm{L} 7 \times \mathrm{T} 1$ & 3706.4 & 4409.6 & 15.9 & 58.8 & 56.5 & 2.7 & 0.9 & 25.9 & 35.9 & 2.6 & 4.5 \\
\hline $\mathrm{L} 8 \times \mathrm{T} 1$ & 3878.8 & 4866.4 & 20.3 & 56.3 & 54.6 & 2.5 & 1.0 & 48.1 & 73.9 & 3.4 & 4.8 \\
\hline $\mathrm{L} 9 \times \mathrm{T} 1$ & 3821.3 & 4819.6 & 20.7 & 59.6 & 57.6 & 2.7 & 0.9 & 31.8 & 52.4 & 2.5 & 3.5 \\
\hline $\mathrm{L} 10 \times \mathrm{T} 1$ & 4066.4 & 5020.9 & 19.0 & 57.5 & 55.8 & 2.8 & 0.9 & 15.5 & 33.9 & 2.9 & 4.3 \\
\hline $\mathrm{L} 11 \times \mathrm{T} 1$ & 3515.4 & 4317.6 & 18.6 & 57.5 & 55.8 & 2.6 & 1.0 & 28.0 & 41.8 & 2.6 & 4.0 \\
\hline $\mathrm{L} 12 \times \mathrm{T} 1$ & 4204.2 & 4522.9 & 7.0 & 61.1 & 58.8 & 2.7 & 1.0 & 11.3 & 24.1 & 2.8 & 3.3 \\
\hline $\mathrm{L} 13 \times \mathrm{T} 1$ & 2912.5 & 3964.7 & 26.5 & 59.9 & 57.5 & 3.3 & 0.9 & 39.6 & 66.4 & 3.1 & 5.1 \\
\hline $\mathrm{L} 14 \times \mathrm{T} 1$ & 4286.3 & 5213.0 & 17.8 & 57.3 & 55.4 & 2.6 & 0.9 & 36.1 & 71.3 & 2.6 & 4.4 \\
\hline $\mathrm{L} 15 \times \mathrm{T} 1$ & 3064.4 & 4465.4 & 31.4 & 57.4 & 55.5 & 3.2 & 1.0 & 34.5 & 45.8 & 3.3 & 4.8 \\
\hline $\mathrm{L} 16 \times \mathrm{T} 1$ & 3124.0 & 4238.5 & 26.3 & 59.5 & 57.5 & 3.1 & 0.9 & 29.8 & 51.8 & 3.3 & 5.0 \\
\hline $\mathrm{L} 17 \times \mathrm{T} 1$ & 3923.2 & 4314.4 & 9.1 & 58.0 & 56.1 & 2.6 & 1.0 & 18.4 & 37.1 & 3.1 & 4.8 \\
\hline $\mathrm{L} 18 \times \mathrm{T} 1$ & 4068.0 & 5090.8 & 20.1 & 59.0 & 56.8 & 2.9 & 1.0 & 25.3 & 30.9 & 3.3 & 4.6 \\
\hline $\mathrm{L} 19 \times \mathrm{T} 1$ & 3921.9 & 4649.2 & 15.6 & 56.9 & 55.5 & 2.7 & 1.0 & 41.3 & 65.5 & 2.9 & 4.9 \\
\hline $\mathrm{L} 20 \times \mathrm{T} 1$ & 2822.8 & 4828.7 & 41.5 & 58.1 & 56.3 & 2.9 & 0.9 & 52.9 & 69.6 & 4.1 & 5.8 \\
\hline $\mathrm{L} 21 \times \mathrm{T} 1$ & 3794.6 & 4072.8 & 6.8 & 57.1 & 55.3 & 2.7 & 1.0 & 37.5 & 54.6 & 2.9 & 4.3 \\
\hline $\mathrm{L} 22 \times \mathrm{T} 1$ & 3026.7 & 3744.6 & 19.2 & 56.5 & 54.6 & 2.8 & 0.9 & 38.3 & 47.9 & 3.3 & 5.0 \\
\hline $\mathrm{L} 23 \times \mathrm{T} 1$ & 3761.7 & 4662.7 & 19.3 & 58.0 & 56.0 & 2.8 & 0.9 & 33.9 & 45.4 & 3.0 & 4.4 \\
\hline $\mathrm{L} 24 \times \mathrm{T} 1$ & 3084.7 & 3793.3 & 18.7 & 58.6 & 56.6 & 3.1 & 0.9 & 25.1 & 46.6 & 3.0 & 4.5 \\
\hline $\mathrm{L} 25 \times \mathrm{T} 1$ & 3478.3 & 5288.0 & 34.2 & 56.1 & 54.3 & 2.9 & 0.9 & 56.1 & 70.3 & 4.3 & 5.6 \\
\hline $\mathrm{L} 26 \times \mathrm{T} 1$ & 3918.3 & 4884.8 & 19.8 & 57.1 & 55.1 & 2.8 & 0.9 & 22.5 & 39.1 & 2.9 & 4.3 \\
\hline $\mathrm{L} 27 \times \mathrm{T} 1$ & 3680.6 & 5340.4 & 31.1 & 58.1 & 56.4 & 2.8 & 0.9 & 51.8 & 75.6 & 3.3 & 4.8 \\
\hline $\mathrm{L} 28 \times \mathrm{T} 1$ & 4161.9 & 5514.3 & 24.5 & 58.5 & 56.9 & 2.8 & 1.0 & 33.9 & 61.9 & 3.0 & 4.5 \\
\hline $\mathrm{L} 29 \times \mathrm{T} 1$ & 4684.6 & 5095.5 & 8.1 & 60.9 & 58.6 & 2.9 & 1.0 & 18.5 & 39.1 & 2.8 & 4.5 \\
\hline $\mathrm{L} 30 \times \mathrm{T} 1$ & 4034.5 & 5038.4 & 19.9 & 58.8 & 57.0 & 2.9 & 0.8 & 21.4 & 32.6 & 3.3 & 5.0 \\
\hline $\mathrm{L} 1 \times \mathrm{T} 2$ & 4314.9 & 5160.9 & 16.4 & 59.3 & 57.1 & 2.9 & 1.0 & 23.5 & 42.5 & 2.9 & 4.1 \\
\hline $\mathrm{L} 2 \times \mathrm{T} 2$ & 3625.2 & 5298.3 & 31.6 & 60.6 & 58.5 & 3.2 & 0.9 & 32.4 & 50.3 & 3.4 & 4.9 \\
\hline $\mathrm{L} 3 \times \mathrm{T} 2$ & 3595.0 & 5309.6 & 32.3 & 61.3 & 59.3 & 3.4 & 0.8 & 19.9 & 46.4 & 3.1 & 5.0 \\
\hline $\mathrm{L} 4 \times \mathrm{T} 2$ & 3973.6 & 4634.3 & 14.3 & 59.6 & 57.6 & 2.9 & 0.9 & 17.0 & 31.5 & 4.3 & 6.3 \\
\hline $\mathrm{L} 5 \times \mathrm{T} 2$ & 3718.5 & 5365.1 & 30.7 & 61.3 & 59.3 & 3.3 & 0.9 & 18.8 & 28.9 & 3.3 & 5.5 \\
\hline $\mathrm{L} 6 \times \mathrm{T} 2$ & 4959.7 & 5785.8 & 14.3 & 58.9 & 56.9 & 2.6 & 1.0 & 21.5 & 38.0 & 2.4 & 3.9 \\
\hline $\mathrm{L} 7 \times \mathrm{T} 2$ & 3861.3 & 4434.4 & 12.9 & 60.5 & 58.0 & 3.1 & 0.9 & 38.5 & 57.4 & 3.1 & 5.5 \\
\hline $\mathrm{L} 8 \times \mathrm{T} 2$ & 3745.1 & 4743.9 & 21.1 & 58.8 & 56.5 & 2.7 & 0.8 & 42.9 & 54.5 & 3.3 & 5.1 \\
\hline $\mathrm{L} 9 \times \mathrm{T} 2$ & 2833.6 & 4007.8 & 29.3 & 61.3 & 59.1 & 3.2 & 0.9 & 38.6 & 62.9 & 2.8 & 5.1 \\
\hline $\mathrm{L} 10 \times \mathrm{T} 2$ & 3545.4 & 4588.6 & 22.7 & 57.9 & 55.6 & 3.1 & 1.0 & 27.0 & 44.1 & 2.6 & 4.6 \\
\hline $\mathrm{L} 11 \times \mathrm{T} 2$ & 3947.3 & 4016.0 & 1.7 & 58.9 & 56.8 & 2.7 & 1.0 & 44.4 & 55.3 & 3.6 & 4.9 \\
\hline $\mathrm{L} 12 \times \mathrm{T} 2$ & 4894.5 & 5380.7 & 9.0 & 60.0 & 58.0 & 2.6 & 0.9 & 11.9 & 23.3 & 3.1 & 4.5 \\
\hline $\mathrm{L} 13 \times \mathrm{T} 2$ & 3135.6 & 4773.0 & 34.3 & 60.4 & 58.1 & 3.3 & 0.8 & 28.4 & 43.1 & 3.6 & 5.5 \\
\hline $\mathrm{L} 14 \times \mathrm{T} 2$ & 4271.7 & 5026.5 & 15.0 & 58.9 & 56.5 & 2.9 & 0.9 & 11.4 & 27.5 & 3.3 & 4.8 \\
\hline $\mathrm{L} 15 \times \mathrm{T} 2$ & 4040.7 & 4616.9 & 12.5 & 58.0 & 56.1 & 2.9 & 1.0 & 24.3 & 34.4 & 3.0 & 5.0 \\
\hline $\mathrm{L} 16 \times \mathrm{T} 2$ & 3840.9 & 5173.6 & 25.8 & 60.1 & 57.6 & 2.9 & 0.9 & 30.5 & 74.3 & 3.0 & 5.0 \\
\hline $\mathrm{L} 17 \times \mathrm{T} 2$ & 3696.2 & 4641.1 & 20.4 & 58.1 & 56.0 & 3.0 & 0.9 & 25.0 & 43.6 & 4.6 & 5.8 \\
\hline $\mathrm{L} 18 \times \mathrm{T} 2$ & 3946.3 & 5717.2 & 31.0 & 60.0 & 57.9 & 2.8 & 0.9 & 31.8 & 54.9 & 3.5 & 5.5 \\
\hline $\mathrm{L} 19 \times \mathrm{T} 2$ & 3744.6 & 4785.2 & 21.7 & 59.4 & 57.1 & 3.0 & 0.9 & 29.3 & 76.8 & 3.5 & 6.4 \\
\hline $\mathrm{L} 20 \times \mathrm{T} 2$ & 4255.3 & 4470.3 & 4.8 & 60.3 & 58.4 & 3.0 & 0.9 & 16.1 & 41.6 & 3.1 & 4.4 \\
\hline $\mathrm{L} 21 \times \mathrm{T} 2$ & 3688.1 & 4295.6 & 14.1 & 60.4 & 58.4 & 2.9 & 0.9 & 26.4 & 35.9 & 3.6 & 5.5 \\
\hline $\mathrm{L} 22 \times \mathrm{T} 2$ & 3753.9 & 4988.7 & 24.8 & 57.3 & 55.1 & 3.0 & 0.9 & 40.5 & 63.0 & 3.3 & 5.3 \\
\hline $\mathrm{L} 23 \times \mathrm{T} 2$ & 4675.2 & 5298.2 & 11.8 & 58.8 & 56.8 & 2.8 & 0.9 & 38.9 & 66.1 & 3.3 & 5.4 \\
\hline $\mathrm{L} 24 \times \mathrm{T} 2$ & 4115.3 & 5218.5 & 21.1 & 60.3 & 58.3 & 3.2 & 0.9 & 14.5 & 24.6 & 3.8 & 4.5 \\
\hline $\mathrm{L} 25 \times \mathrm{T} 2$ & 4728.0 & 5651.6 & 16.3 & 56.4 & 54.8 & 2.8 & 0.9 & 38.8 & 47.8 & 3.8 & 4.6 \\
\hline $\mathrm{L} 26 \times \mathrm{T} 2$ & 3319.7 & 4813.7 & 31.0 & 57.8 & 55.9 & 3.3 & 0.9 & 27.4 & 43.3 & 3.0 & 4.1 \\
\hline $\mathrm{L} 27 \times \mathrm{T} 2$ & 3466.0 & 5161.8 & 32.9 & 58.3 & 56.8 & 3.2 & 0.9 & 37.5 & 60.1 & 3.4 & 5.4 \\
\hline $\mathrm{L} 28 \times \mathrm{T} 2$ & 3277.3 & 4102.5 & 20.1 & 62.6 & 60.4 & 3.4 & 0.8 & 23.9 & 50.9 & 2.6 & 4.5 \\
\hline $\mathrm{L} 29 \times \mathrm{T} 2$ & 2740.8 & 2926.2 & 6.3 & 62.4 & 60.8 & 3.7 & 0.7 & 13.6 & 31.1 & 3.5 & 4.8 \\
\hline $\mathrm{L} 30 \times \mathrm{T} 2$ & 2733.9 & 3715.3 & 26.4 & 61.9 & 59.5 & 3.4 & 0.8 & 33.3 & 42.5 & 4.0 & 6.6 \\
\hline $\mathrm{L} 1 \times \mathrm{T} 3$ & 3488.2 & 4323.4 & 19.3 & 56.8 & 54.5 & 2.9 & 0.9 & 34.3 & 46.3 & 3.9 & 5.6 \\
\hline $\mathrm{L} 2 \times \mathrm{T} 3$ & 3198.5 & 4493.6 & 28.8 & 58.5 & 56.5 & 2.9 & 0.9 & 33.1 & 49.9 & 4.5 & 6.1 \\
\hline $\mathrm{L} 3 \times \mathrm{T} 3$ & 4074.4 & 4738.4 & 14.0 & 57.5 & 55.5 & 2.9 & 0.9 & 17.5 & 36.8 & 3.1 & 4.9 \\
\hline $\mathrm{L} 4 \times \mathrm{T} 3$ & 2832.5 & 3806.8 & 25.6 & 57.3 & 55.4 & 3.3 & 0.8 & 41.4 & 52.4 & 4.4 & 6.3 \\
\hline $\mathrm{L} 5 \times \mathrm{T} 3$ & 2755.8 & 4152.8 & 33.6 & 59.0 & 56.5 & 3.4 & 0.8 & 35.8 & 57.4 & 4.0 & 5.9 \\
\hline
\end{tabular}


Table A3. Cont.

\begin{tabular}{|c|c|c|c|c|c|c|c|c|c|c|c|}
\hline Testcrosses & YLDIN & YLDUN & RED (\%) & DYSK & DYSP & EASP & EPP & $\mathrm{CO} 1$ & $\mathrm{CO} 2$ & RAT1 & RRAT2 \\
\hline $\mathrm{L} 7 \times \mathrm{T} 3$ & 2512.2 & 4076.1 & 38.4 & 56.9 & 54.9 & 3.2 & 0.7 & 42.6 & 74.8 & 4.5 & 6.4 \\
\hline $\mathrm{L} 9 \times \mathrm{T} 3$ & 2709.3 & 3029.1 & 10.6 & 58.3 & 56.1 & 3.2 & 0.9 & 31.9 & 51.1 & 3.4 & 5.3 \\
\hline $\mathrm{L} 10 \times \mathrm{T} 3$ & 2876.5 & 3798.8 & 24.3 & 56.3 & 54.4 & 3.4 & 0.9 & 33.6 & 43.4 & 3.8 & 5.3 \\
\hline $\mathrm{L} 11 \times \mathrm{T} 3$ & 2610.6 & 4074.7 & 35.9 & 55.8 & 53.8 & 3.2 & 0.8 & 36.1 & 53.0 & 4.1 & 6.3 \\
\hline $\mathrm{L} 14 \times \mathrm{T} 3$ & 3576.3 & 4027.0 & 11.2 & 55.8 & 54.1 & 2.8 & 0.9 & 24.4 & 39.8 & 3.6 & 4.9 \\
\hline $\mathrm{L} 15 \times \mathrm{T} 3$ & 2350.8 & 3587.4 & 34.5 & 55.9 & 53.8 & 3.3 & 0.8 & 37.8 & 65.0 & 4.5 & 6.8 \\
\hline $\mathrm{L} 16 \times \mathrm{T} 3$ & 3255.8 & 3793.4 & 14.2 & 56.8 & 54.6 & 3.0 & 0.9 & 27.4 & 42.9 & 3.5 & 5.4 \\
\hline $\mathrm{L} 17 \times \mathrm{T} 3$ & 2990.0 & 4176.8 & 28.4 & 55.8 & 53.9 & 3.3 & 0.8 & 25.8 & 38.9 & 4.1 & 5.5 \\
\hline $\mathrm{L} 18 \times \mathrm{T} 3$ & 3387.8 & 4265.6 & 20.6 & 57.1 & 55.1 & 2.9 & 0.9 & 27.5 & 59.1 & 4.3 & 5.9 \\
\hline $\mathrm{L} 22 \times \mathrm{T} 3$ & 3147.1 & 4263.5 & 26.2 & 54.1 & 52.8 & 3.1 & 0.9 & 53.4 & 78.5 & 4.4 & 6.8 \\
\hline $\mathrm{L} 23 \times \mathrm{T} 3$ & 3337.0 & 4374.1 & 23.7 & 55.4 & 53.5 & 2.8 & 0.8 & 71.3 & 85.4 & 4.1 & 5.8 \\
\hline $\mathrm{L} 24 \times \mathrm{T} 3$ & 2618.9 & 4069.8 & 35.7 & 59.1 & 57.1 & 3.3 & 0.7 & 33.9 & 52.3 & 4.0 & 6.1 \\
\hline $\mathrm{L} 25 \times \mathrm{T} 3$ & 3257.7 & 4391.2 & 25.8 & 55.0 & 53.3 & 3.0 & 1.0 & 55.9 & 72.8 & 4.3 & 6.0 \\
\hline $\mathrm{L} 26 \times \mathrm{T} 3$ & 2763.4 & 4180.0 & 33.9 & 55.0 & 53.6 & 3.2 & 0.9 & 45.9 & 50.8 & 3.8 & 5.1 \\
\hline $\mathrm{L} 27 \times \mathrm{T} 3$ & 2654.8 & 4481.6 & 40.8 & 56.9 & 55.0 & 3.1 & 0.7 & 50.1 & 74.3 & 4.6 & 6.6 \\
\hline $\mathrm{L} 28 \times \mathrm{T} 3$ & 2918.0 & 4393.9 & 33.6 & 57.6 & 55.6 & 2.9 & 0.7 & 49.6 & 87.9 & 3.6 & 5.8 \\
\hline $\mathrm{L} 29 \times \mathrm{T} 3$ & 2707.4 & 3964.8 & 31.7 & 59.8 & 57.8 & 3.6 & 0.8 & 26.3 & 29.0 & 4.5 & 6.0 \\
\hline $\mathrm{L} 30 \times \mathrm{T} 3$ & 2293.3 & 3957.4 & 42.1 & 59.0 & 57.0 & 3.3 & 0.7 & 28.6 & 48.9 & 4.9 & 6.4 \\
\hline $8425-8$ & 2280.7 & 4174.1 & 45.4 & 59.1 & 56.8 & 3.5 & 0.8 & 37.3 & 59.3 & 4.4 & 6.4 \\
\hline 8338-3 & 1050.3 & 3303.9 & 68.2 & 60.9 & 59.0 & 4.2 & 0.3 & 92.1 & 132.6 & 6.6 & 8.6 \\
\hline
\end{tabular}

DYSK $=$ days to $50 \%$ silking, DYSP $=$ days to $50 \%$ anthesis, PLHT $=$ plant height $(\mathrm{cm})$, RAT1 and RAT2 $=$ Striga damage rating (scale of 1-9) at 8 and $10 \mathrm{WAP}$, respectively, CO1 and CO2 = Striga emergence count at 8 and 10 WAP, respectively, EASP = ear aspect (rating at a scale of 1-5), EHT = plant height from base to the node of the ear $(\mathrm{cm})$, PASP = qualitative observation of plant ideotype rated using a scale of 1 to 5 , HUSK $=$ the degree of the husk covering the tip of the ear using a scale of 1 to 5, ASI = anthesis-silking interval, EPP = ears per plant, YLDIN and YLDUN = grain yield ( $\mathrm{kg} / \mathrm{ha}$ ) under Striga-infested and non-infested conditions and RED $\%=$ per cent grain yield reduction due to Striga infestation.

Table A4. Consistency of line and tester rankings using Kendall's coefficient of concordance (W) across environment under (a) Striga-infested and (b) non-infested conditions.

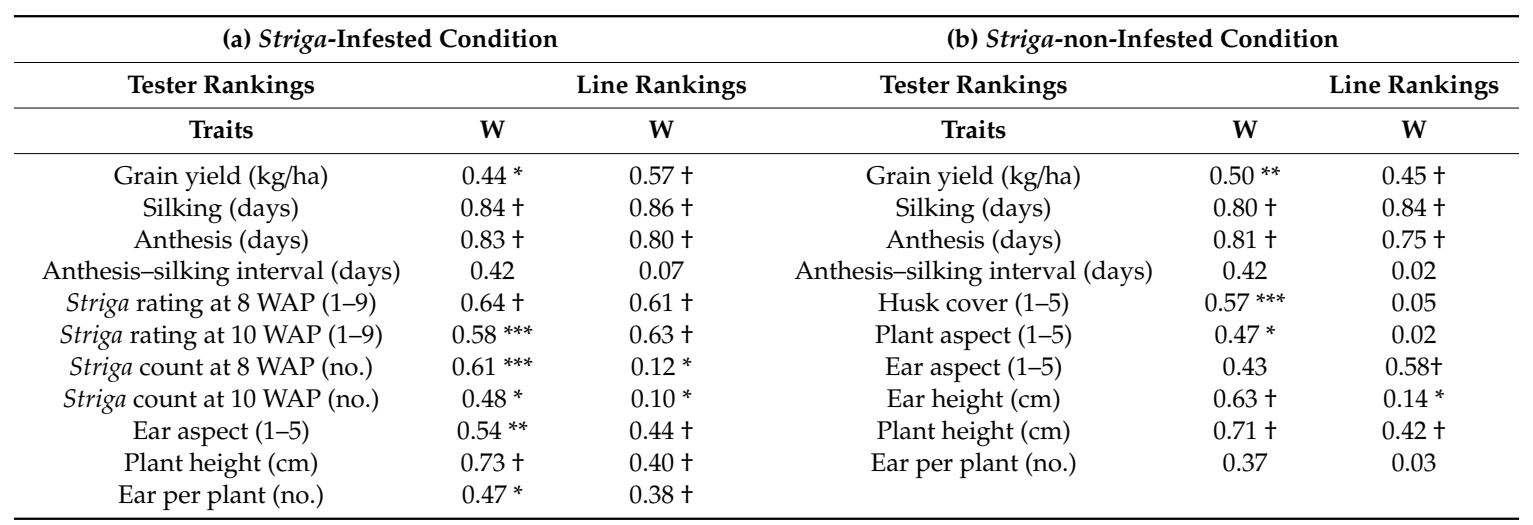

$* * * * * *,+$ significant at $p<0.05,0.01,0.001$ and 0.0001 levels, respectively. WAP $=$ weeks after planting. 
Table A5. Kendall's coefficient of concordance (W) based on BLUP for ranks of yellow maize inbred lines by each tester across environments under Striga-infested and non-infested conditions.

\begin{tabular}{|c|c|c|c|c|c|c|c|}
\hline \multicolumn{4}{|c|}{ Striga-Infested Condition } & \multicolumn{4}{|c|}{ Striga-non-Infested Condition } \\
\hline Traits & T1 & $\mathrm{T} 2$ & T3 & Traits & T1 & T2 & T3 \\
\hline Grain yield (kg/ha) & $0.38 *$ & $0.38 *$ & $0.42 * *$ & Grain yield (kg/ha) & $0.39 * *$ & $0.41^{* *}$ & 0.31 \\
\hline Silking (days) & $0.55+$ & $0.74+$ & $0.51+$ & Silking (days) & $0.53+$ & $0.69+$ & $0.52+$ \\
\hline Anthesis (days) & $0.55+$ & $0.75+$ & $0.47^{* * *}$ & Anthesis (days) & $0.53+$ & $0.74+$ & $0.52+$ \\
\hline Anthesis-silking interval (days) & 0.21 & 0.26 & 0.24 & Anthesis-silking interval (days) & 0.19 & 0.30 & 0.28 \\
\hline Striga rating at 8 WAP (1-9) & 0.32 & 0.33 & 035 * & Husk cover (1-5) & 0.23 & 0.28 & 0.33 \\
\hline Striga rating at 10 WAP (1-9) & $0.39 * *$ & 0.33 & 0.33 & Plant aspect (1-5) & 0.25 & 0.33 & 0.26 \\
\hline Striga count at 8 WAP (no.) & $0.43 * *$ & $0.48^{* * *}$ & $0.45^{* *}$ & Ear height $(\mathrm{cm})$ & $0.59+$ & $0.56+$ & $0.54+$ \\
\hline Striga count at 10 WAP (no.) & 0.32 & $0.42 * *$ & $0.36 *$ & Ear aspect $(1-5)$ & 0.28 & 0.34 & 0.35 * \\
\hline Ear aspect (1-5) & 0.26 & $0.48 * * *$ & $0.35 *$ & Plant height $(\mathrm{cm})$ & $0.64+$ & $0.62+$ & $0.61+$ \\
\hline Plant height $(\mathrm{cm})$ & $0.51+$ & $0.54+$ & $0.61+$ & Ear per plant (no.) & 0.15 & $0.44^{* * *}$ & 0.19 \\
\hline Ear per plant (no.) & $0.36 *$ & $0.44 * * *$ & $0.41^{* *}$ & & & & \\
\hline
\end{tabular}

$*{ }^{* *},{ }^{* * *},+$ significant at $p<0.05,0.01,0.001$ and 0.0001 levels, respectively. WAP $=$ weeks after planting. $\mathrm{T} 1=$ Tolerant tester, $\mathrm{T} 2=$ Resistant tester and $\mathrm{T} 3=$ Susceptible tester.

Table A6. Ranking Striga-resistant inbred lines based on average yield ( $\mathrm{kg} / \mathrm{ha}$ ) performance across each environment in the combined analysis at Abuja and Mokwa, Nigeria for each tester under Striga infestation.

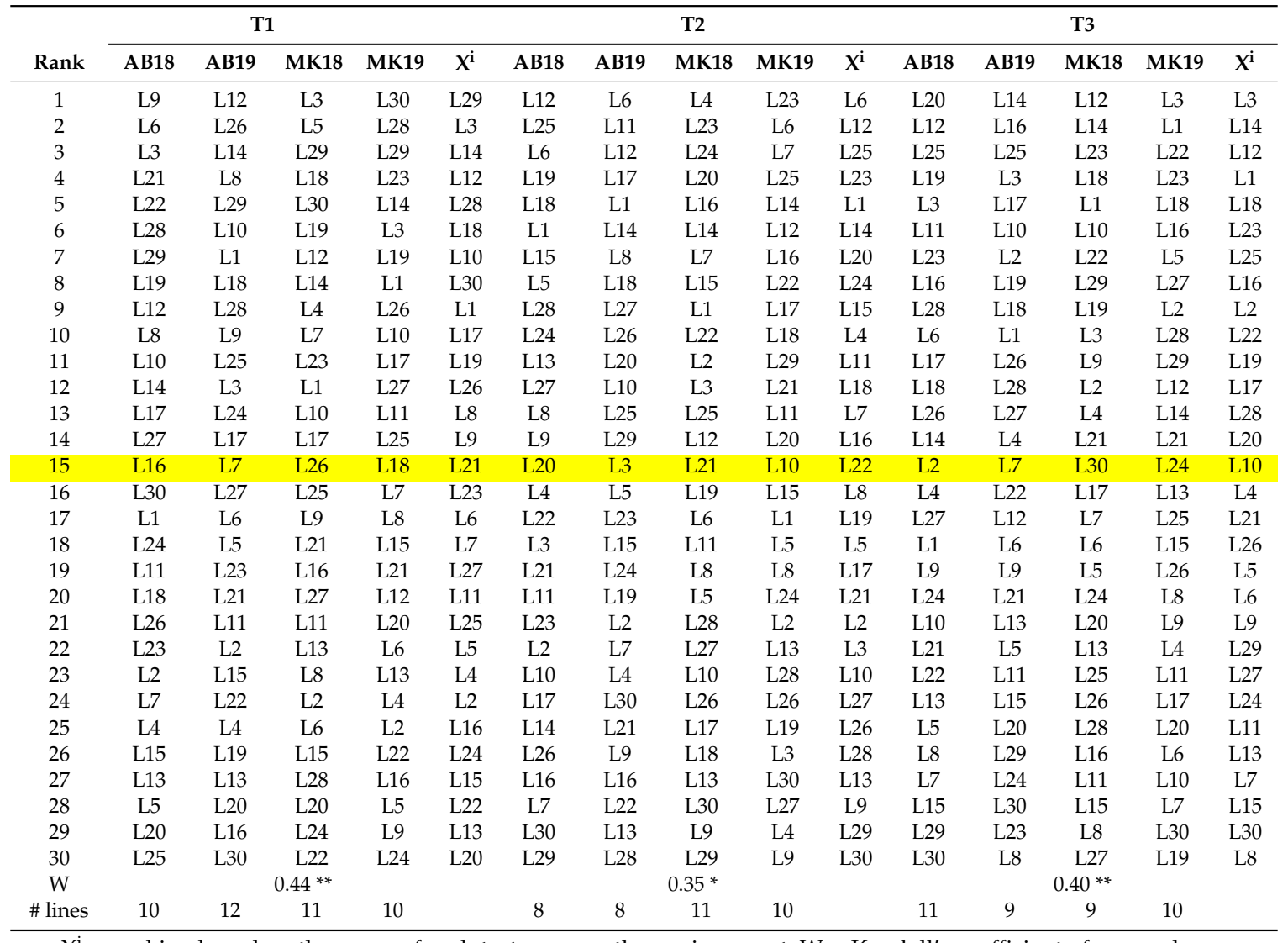

$\mathrm{X}^{\mathrm{i}}=$ ranking based on the mean of each tester across the environment; $\mathrm{W}=$ Kendall's coefficient of concordance where ${ }^{*}$ and ${ }^{* *}$ are significant levels of probability at 0.05 and 0.01, respectively. AB18, AB19, MK18 and MK19 are Abuja and Mokwa environments in the 2018 and 2019 cropping seasons, respectively; note: number of lines (\# lines) are based on top 15 lines ranks indicated in yellow color in descending order, i.e., inbred lines performed best ranked first and poor performing inbred lines ranked last. 
Table A7. Ranking of Striga-resistant inbred lines based on average yield ( $\mathrm{kg} / \mathrm{ha}$ performance across each environment in the combined analysis at Abuja and Mokwa, Nigeria for each tester in the Striga-non-infested condition.

\begin{tabular}{|c|c|c|c|c|c|c|c|c|c|c|c|c|c|c|c|}
\hline \multirow[b]{2}{*}{ Rank } & \multicolumn{5}{|c|}{ T1 } & \multicolumn{5}{|c|}{$\mathrm{T} 2$} & \multicolumn{5}{|c|}{ T3 } \\
\hline & AB18 & AB19 & MK18 & MK19 & $\mathbf{X i}$ & AB18 & AB19 & MK18 & MK19 & $\mathbf{X i}$ & AB18 & AB19 & MK18 & MK19 & $\mathbf{X i}$ \\
\hline 1 & L30 & L9 & L29 & L10 & L28 & L25 & L27 & L5 & L5 & L6 & L28 & L3 & L11 & L3 & L3 \\
\hline 2 & L27 & L12 & L28 & L28 & L27 & L6 & L18 & L24 & L14 & L18 & L20 & L11 & L16 & L27 & L2 \\
\hline 3 & L14 & L1 & L3 & L3 & L25 & L3 & L6 & L18 & L16 & L25 & L11 & L5 & L21 & L25 & L27 \\
\hline 4 & L10 & L25 & L27 & L26 & L14 & L22 & L5 & L3 & L25 & L12 & L27 & L29 & L9 & L16 & L28 \\
\hline 5 & L15 & L28 & L19 & L14 & L29 & L18 & L12 & L16 & L23 & L5 & L6 & L1 & L3 & L1 & L25 \\
\hline 6 & L2 & L27 & L8 & L18 & L18 & L23 & L10 & L2 & L8 & L3 & L3 & L7 & L15 & L2 & L23 \\
\hline 7 & L18 & L10 & L25 & L25 & L30 & L27 & L1 & L13 & L12 & L2 & L2 & L18 & L29 & L24 & L1 \\
\hline 8 & L16 & L26 & L18 & L21 & L3 & L8 & L2 & L21 & L2 & L23 & L24 & L22 & L24 & L28 & L18 \\
\hline 9 & L29 & L5 & L20 & L5 & L10 & L26 & L25 & L7 & L13 & L24 & L22 & L2 & L20 & L13 & L22 \\
\hline 10 & L8 & L3 & L26 & L20 & L26 & L1 & L14 & L10 & L6 & L16 & L23 & L23 & L19 & L18 & L26 \\
\hline 11 & L25 & L13 & L14 & L30 & L8 & L17 & L30 & L23 & L20 & L27 & $\mathrm{L} 4$ & L25 & L10 & L17 & L17 \\
\hline 12 & L9 & L17 & L21 & L23 & L20 & L12 & L11 & L15 & L24 & L1 & L26 & L15 & L27 & L19 & L5 \\
\hline 13 & L6 & L29 & L23 & L12 & L9 & L13 & L26 & L6 & L7 & L14 & L17 & L12 & L28 & L8 & L7 \\
\hline 14 & L28 & L14 & L7 & L29 & L5 & L19 & L16 & L1 & L26 & L22 & L16 & L13 & L4 & L5 & L11 \\
\hline 15 & L19 & L24 & L30 & L8 & L23 & L4 & L28 & L12 & L15 & L26 & L29 & L17 & L13 & L10 & L24 \\
\hline 16 & L20 & L18 & L5 & L11 & L19 & L24 & L4 & L22 & L3 & L19 & L14 & L21 & L2 & L21 & L20 \\
\hline 17 & L22 & L7 & L13 & L19 & L1 & L14 & L17 & L9 & L29 & L13 & L8 & L14 & L22 & L14 & L14 \\
\hline 18 & L23 & L8 & L9 & L15 & L12 & L28 & L19 & $\mathrm{L} 4$ & L19 & L8 & L25 & L26 & L17 & L11 & L12 \\
\hline 19 & L11 & L2 & L6 & L1 & L15 & L2 & L15 & L25 & L18 & L17 & L10 & L16 & L5 & L26 & L6 \\
\hline 20 & L12 & L20 & L2 & L27 & L2 & L11 & L22 & L19 & L22 & L4 & L18 & L30 & L8 & L22 & L29 \\
\hline 21 & L5 & L6 & L11 & L7 & L7 & L20 & L21 & L20 & L28 & L15 & L15 & L10 & L6 & L23 & L30 \\
\hline 22 & L7 & L16 & L17 & L17 & L6 & L9 & L23 & L17 & L1 & L10 & L5 & L24 & L14 & $\mathrm{L} 4$ & L8 \\
\hline 23 & L1 & L4 & L1 & L22 & L11 & L15 & L3 & L27 & L21 & L20 & L7 & L27 & L1 & L7 & L13 \\
\hline 24 & L17 & L23 & L15 & L6 & L17 & L29 & L24 & L11 & L10 & L7 & L30 & L19 & L25 & L20 & L4 \\
\hline 25 & L3 & L15 & L16 & L9 & L16 & L16 & L8 & L14 & L27 & L21 & L1 & L8 & L7 & L29 & L10 \\
\hline 26 & L4 & L30 & L24 & L2 & L21 & L7 & L9 & L8 & L17 & L28 & L9 & L20 & L18 & L12 & L16 \\
\hline 27 & L26 & L22 & $\mathrm{L} 4$ & L4 & L13 & L10 & L20 & L26 & L4 & L11 & L21 & L6 & L26 & L30 & L15 \\
\hline 28 & L24 & L11 & L10 & L13 & L4 & L21 & L7 & L30 & L30 & L9 & L12 & L9 & L23 & L15 & L19 \\
\hline 29 & L21 & L19 & L12 & L16 & L24 & L30 & L13 & L28 & L9 & L30 & L19 & L4 & L12 & L9 & L21 \\
\hline 30 & L13 & L21 & L22 & L24 & L22 & L5 & L29 & L29 & L11 & L29 & L13 & L28 & L30 & L6 & L9 \\
\hline W & & & $0.39^{* *}$ & & & & & 0.33 & & & & & 0.25 & & \\
\hline \# line & 10 & 10 & 12 & 13 & & 9 & 12 & 11 & 10 & & 9 & 10 & 5 & 9 & \\
\hline
\end{tabular}

$\mathrm{X}^{\mathrm{i}}=$ Ranking based on the mean of each tester across the environment; $\mathrm{W}=$ Kendall's coefficient of concordance where $^{* *}=$ significant levels of probability at 0.01. AB18, AB19, MK18 and MK19 are Abuja and Mokwa environments in the 2018 and 2019 cropping seasons, respectively; note: number of lines (\# lines) is based on the top 15 lines ranks indicated in yellow color in descending order, i.e., inbred lines performed best ranked first and poor performing inbred lines ranked last.

Table A8. Ranking Striga-resistant inbred lines for Striga rating (1-9 scale) at 10 WAP across each environment in the combined analysis at Abuja and Mokwa, Nigeria for each tester.

\begin{tabular}{|c|c|c|c|c|c|c|c|c|c|c|c|c|c|c|c|}
\hline Rank & AB18 & \multicolumn{4}{|c|}{ T1 } & \multicolumn{5}{|c|}{$\mathrm{T} 2$} & \multicolumn{5}{|c|}{ T3 } \\
\hline 1 & L9 & L2 & L12 & L11 & L12 & L26 & L6 & L24 & L16 & L6 & L12 & L16 & L3 & L23 & L14 \\
\hline 3 & L28 & L9 & L11 & L2 & L1 & L1 & L29 & L14 & L2 & L20 & L19 & L3 & L9 & L1 & L21 \\
\hline 4 & L3 & L12 & L2 & L1 & L6 & L6 & L24 & L6 & L11 & L1 & L20 & L10 & L6 & L8 & L26 \\
\hline 5 & L6 & L3 & L1 & L23 & L2 & L10 & L17 & L28 & L14 & L24 & L3 & L26 & L29 & L17 & L10 \\
\hline 8 & L24 & L8 & L18 & L27 & L21 & L13 & L8 & L29 & L3 & L25 & L16 & L25 & L19 & L20 & L16 \\
\hline 9 & L26 & L26 & L7 & L9 & L26 & L20 & L1 & L26 & L1 & L12 & L21 & L18 & L23 & L18 & L9 \\
\hline 10 & L29 & L29 & L19 & L21 & L14 & L3 & L11 & L10 & L6 & L14 & L7 & L21 & L4 & L3 & L20 \\
\hline 11 & L1 & L1 & L10 & L18 & L23 & L9 & L25 & L15 & L28 & L29 & L24 & L5 & L16 & L14 & L17 \\
\hline 12 & L7 & L21 & L29 & L7 & L3 & L11 & L2 & L16 & L26 & L3 & L26 & L2 & L10 & L12 & L18 \\
\hline 13 & L13 & $\mathrm{L} 4$ & L3 & L19 & L7 & L16 & L10 & L23 & L10 & L15 & L28 & L15 & L21 & L28 & L23 \\
\hline 18 & L21 & L18 & L28 & $\mathrm{L} 4$ & L18 & L18 & L15 & L25 & L20 & L9 & L23 & L28 & L11 & $\mathrm{L} 4$ & L13 \\
\hline 19 & L22 & L25 & L24 & L28 & L8 & L21 & L9 & L27 & L12 & L21 & L25 & L30 & L5 & L10 & L2 \\
\hline 20 & L30 & L28 & L17 & L8 & L15 & L23 & L5 & L7 & L7 & L23 & L27 & L29 & L20 & L2 & L24 \\
\hline 21 & L4 & L7 & L14 & L24 & L17 & L25 & L7 & L18 & L18 & L27 & L30 & L20 & L7 & L24 & L25 \\
\hline
\end{tabular}


Table A8. Cont.

\begin{tabular}{|c|c|c|c|c|c|c|c|c|c|c|c|c|c|c|c|}
\hline \multirow[b]{2}{*}{ Rank } & \multirow[b]{2}{*}{ AB18 } & \multicolumn{4}{|c|}{ T1 } & \multicolumn{5}{|c|}{$\mathrm{T} 2$} & \multicolumn{5}{|c|}{ T3 } \\
\hline & & AB19 & MK18 & MK19 & $X^{i}$ & AB18 & AB19 & MK18 & MK19 & $X^{i}$ & AB18 & AB19 & MK18 & MK19 & $X^{i}$ \\
\hline 22 & L8 & L13 & L13 & L17 & L27 & L27 & L18 & $\mathrm{L} 21$ & L5 & $\mathrm{L} 22$ & L4 & L7 & $\mathrm{L} 24$ & L30 & L29 \\
\hline 24 & L18 & L27 & L27 & $\mathrm{L} 25$ & L16 & L7 & $\mathrm{L} 21$ & L3 & L15 & L5 & L18 & L13 & L1 & L29 & L7 \\
\hline 25 & L19 & L5 & $\mathrm{L} 22$ & L10 & L22 & L14 & L22 & L5 & $\mathrm{L} 27$ & L7 & $\mathrm{L} 22$ & $\mathrm{~L} 27$ & L18 & L19 & L30 \\
\hline 26 & L27 & L22 & L20 & L14 & L30 & L22 & L30 & L13 & $\mathrm{L} 4$ & L13 & L29 & $\mathrm{L} 23$ & L15 & L27 & L4 \\
\hline 29 & $\mathrm{~L} 25$ & L20 & L16 & L13 & L25 & L30 & L23 & L11 & L30 & L4 & L15 & L22 & L30 & $\mathrm{L} 15$ & $\mathrm{~L} 27$ \\
\hline 30 & L20 & L30 & $\mathrm{L} 25$ & L3 & L20 & L17 & $\mathrm{L} 4$ & L30 & L19 & L30 & L17 & L8 & $\mathrm{L} 27$ & L16 & L15 \\
\hline W & \multicolumn{2}{|c|}{$0.38 *$} & & & & $0.35 *$ & & & & & 0.32 & & & & \\
\hline \# lines & 13 & 12 & 11 & 8 & & 11 & 11 & 11 & 10 & & 11 & 10 & 12 & 11 & \\
\hline
\end{tabular}

$\mathrm{X}^{\mathrm{i}}=$ ranking based on the mean of each tester across the environment; $\mathrm{W}=$ Kendall's coefficient of concordance where * $=$ significant levels of probability at 0.05. AB18, AB19, MK18 and MK19 are Abuja and Mokwa environments in the 2018 and 2019 cropping seasons, respectively; note: number of lines (\# lines) is based on the top 15 lines highlighted in yellow color in ascending order, i.e., inbred lines with lower value ranked $1=$ resistant, and highly scored inbred lines ranked 30, which is susceptible. WAP = weeks after planting.

Table A9. (a) Estimates of specific combining ability (SCA) effects of selected line $\times$ tester crosses evaluated for grain yield and other related traits across environments under Striga infestation. (b) Estimates of specific combining ability (SCA) effects of selected line $\times$ tester crosses evaluated for Striga resistance and agro-morphological traits at Mokwa and Abuja in the combined analysis under the Striga non-infested condition.

\begin{tabular}{|c|c|c|c|c|c|c|c|c|c|c|}
\hline \multicolumn{11}{|c|}{ (a) } \\
\hline Crosses & DYSK & DYSP & RAT1 & RAT2 & CO1 & $\mathrm{CO} 2$ & EASP & EPP & YLD & YLDUN \\
\hline $\mathrm{L} 1 \times \mathrm{T} 1$ & 0.64 & 0.73 & -0.19 & -0.08 & -8.71 & -7.7 & -0.05 & 0.017 & -145.3 & -286.7 \\
\hline $\mathrm{L} 2 \times \mathrm{T} 1$ & 0.18 & 0.27 & 0.19 & -0.41 & -3.38 & -7.24 & 0.03 & -0.044 & -343.9 & -443.9 \\
\hline $\mathrm{L} 3 \times \mathrm{T} 1$ & -0.61 & -0.48 & 0.14 & 0.3 & -0.09 & -9.07 & -0.22 & 0.018 & 295.7 & -142.6 \\
\hline $\mathrm{L} 4 \times \mathrm{T} 1$ & 0.60 & 0.43 & -0.31 & -0.49 & 10.83 & 14.76 & 0.07 & 0.049 & -303.1 & -368.9 \\
\hline $\mathrm{L} 5 \times \mathrm{T} 1$ & 0.14 & 0.18 & $0.48^{*}$ & 0.55 & 5.29 & 7.55 & 0.03 & -0.023 & -142.3 & -122.8 \\
\hline $\mathrm{L} 6 \times \mathrm{T} 1$ & 0.68 & 0.77 & 0.14 & 0.01 & 8.46 & 6.26 & 0.15 & 0.017 & -305.4 & -476.3 \\
\hline $\mathrm{L} 7 \times \mathrm{T} 1$ & -0.07 & -0.11 & -0.4 & -0.37 & -9.34 & -18.99 & -0.14 & 0.004 & 125.1 & -46.3 \\
\hline $\mathrm{L} 8 \times \mathrm{T} 1$ & -0.63 & -0.98 & 0.02 & -0.12 & -8.13 & 2.76 & -0.18 & 0.116 & 438.8 & 201.6 \\
\hline $\mathrm{L} 9 \times \mathrm{T} 1$ & -0.19 & -0.15 & 0.02 & -0.53 & -1.88 & -1.95 & -0.16 & 0.016 & 478.5 & $718.3^{*}$ \\
\hline $\mathrm{L} 10 \times \mathrm{T} 1$ & 0.18 & 0.35 & 0.19 & 0.13 & -9.42 & -5.45 & -0.14 & -0.052 & 348.9 & 402.3 \\
\hline $\mathrm{L} 11 \times \mathrm{T} 1$ & 0.01 & 0.18 & -0.44 & -0.45 & -7.71 & -7.11 & -0.03 & -0.004 & -63.8 & 32.3 \\
\hline $\mathrm{L} 12 \times \mathrm{T} 1$ & 0.93 & 0.68 & -0.02 & -0.49 & -3.42 & -5.16 & 0.11 & 0.005 & -221.8 & -258.1 \\
\hline $\mathrm{L} 13 \times \mathrm{T} 1$ & 0.68 & 0.60 & -0.11 & 0.22 & 4.37 & 12.39 & 0.16 & -0.004 & -190 & -376.1 \\
\hline $\mathrm{L} 14 \times \mathrm{T} 1$ & -0.15 & -0.11 & -0.15 & 0.3 & $12.62 *$ & $26.22 *$ & 0.03 & -0.019 & 20.1 & 308.3 \\
\hline $\mathrm{L} 15 \times \mathrm{T} 1$ & 0.18 & 0.23 & 0.06 & -0.16 & 2.79 & -1.49 & $0.26^{*}$ & 0.044 & -309 & 92.9 \\
\hline $\mathrm{L} 16 \times \mathrm{T} 1$ & 0.60 & 0.77 & 0.39 & 0.47 & 1.00 & -3.41 & 0.30 ** & 0.02 & -504.3 & -312.5 \\
\hline $\mathrm{L} 17 \times \mathrm{T} 1$ & 0.60 & 0.64 & -0.44 & 0.01 & -4.21 & -1.61 & -0.18 & 0.016 & 165.3 & -212.3 \\
\hline $\mathrm{L} 18 \times \mathrm{T} 1$ & 0.18 & 0.02 & -0.02 & -0.12 & -2.46 & -16.28 & 0.18 & 0.026 & 45.9 & -82.9 \\
\hline $\mathrm{L} 19 \times \mathrm{T} 1$ & -0.82 & -0.44 & 0.02 & -0.12 & 10.54 & 9.18 & -0.05 & -0.051 & 120.5 & 183.8 \\
\hline $\mathrm{L} 20 \times \mathrm{T} 1$ & -0.24 & -0.32 & $0.81^{* * *}$ & $1.09^{* *}$ & $20.87^{* *}$ & 20.39 & 0.07 & -0.031 & $-721.8^{* *}$ & 236.9 \\
\hline $\mathrm{L} 21 \times \mathrm{T} 1$ & -1.03 * & $-0.98 *$ & -0.15 & -0.16 & 4.66 & 6.39 & -0.05 & 0.007 & 152.6 & 38.9 \\
\hline $\mathrm{L} 22 \times \mathrm{T} 1$ & 0.43 & 0.31 & 0.02 & -0.08 & -5.34 & -14.11 & 0.01 & -0.036 & -503.9 & -736.8 \\
\hline $\mathrm{L} 23 \times \mathrm{T} 1$ & 0.51 & 0.43 & -0.06 & -0.2 & $-13.7 *$ & -19.11 & 0.2 & 0.027 & -384.4 & -264.9 \\
\hline $\mathrm{L} 24 \times \mathrm{T} 1$ & -0.82 & -0.86 & -0.19 & 0.05 & 1.08 & 6.59 & 0.09 & 0.048 & -409.6 & -716.5 * \\
\hline $\mathrm{L} 25 \times \mathrm{T} 1$ & 0.18 & 0.02 & $0.56 *$ & 0.80 * & 6.33 & 7.8 & 0.18 & -0.084 & $-564.4^{*}$ & 28.5 \\
\hline $\mathrm{L} 26 \times \mathrm{T} 1$ & 0.39 & 0.10 & 0.06 & 0.34 & -8.96 & -4.11 & -0.14 & 0.006 & 363.1 & 109.4 \\
\hline $\mathrm{L} 27 \times \mathrm{T} 1$ & 0.26 & 0.18 & -0.11 & -0.24 & 5.75 & 6.76 & -0.05 & 0.03 & 192.1 & 196.6 \\
\hline $\mathrm{L} 28 \times \mathrm{T} 1$ & -1.19 * & $-0.9^{* *}$ & 0.31 & 0.17 & -1.46 & -3.86 & -0.07 & 0.059 & 488.1 & $694.9 *$ \\
\hline $\mathrm{L} 29 \times \mathrm{T} 1$ & -0.24 & -0.57 & -0.44 & 0.01 & -0.5 & 7.18 & $-0.3^{* *}$ & $-0.18^{*}$ & $1085.6^{* * *}$ & $950.8^{* *}$ \\
\hline $\mathrm{L} 30 \times \mathrm{T} 1$ & -1.24 * & -0.98 * & -0.4 & -0.41 & -5.92 & -7.57 & -0.14 & 0.003 & $792.6^{* *}$ & 652.2 \\
\hline $\mathrm{L} 1 \times \mathrm{T} 2$ & -0.42 & -0.32 & -0.06 & -0.34 & 3.95 & 6.41 & 0.05 & -0.044 & 44 & 176.8 \\
\hline $\mathrm{L} 2 \times \mathrm{T} 2$ & -0.38 & -0.40 & -0.31 & -0.05 & 6.28 & 8.24 & 0.2 & 0.007 & -56.7 & 239.0 \\
\hline $\mathrm{L} 3 \times \mathrm{T} 2$ & 0.83 & 0.85 & 0.28 & 0.28 & 6.2 & 13.78 & $0.45^{* * *}$ & -0.047 & $-829.6^{* *}$ & -28.4 \\
\hline $\mathrm{L} 4 \times \mathrm{T} 2$ & -0.47 & -0.36 & 0.44 & 0.62 & -12.6 * & -13.38 & -0.14 & -0.047 & 280.1 & 212.9 \\
\hline $\mathrm{L} 5 \times \mathrm{T} 2$ & -0.30 & 0.02 & -0.26 & -0.09 & -6.18 & -13.59 & -0.05 & 0.02 & 110.5 & 282.3 \\
\hline $\mathrm{L} 6 \times \mathrm{T} 2$ & -0.88 & $-0.9 * * *$ & -0.22 & -0.51 & -5.39 & -7.88 & -0.18 & 0.001 & $830.1^{* *}$ & $760.9 *$ \\
\hline $\mathrm{L} 7 \times \mathrm{T} 2$ & 0.49 & 0.35 & -0.14 & 0.12 & 7.57 & 5.24 & 0.09 & -0.012 & 170 & -183.0 \\
\hline $\mathrm{L} 8 \times \mathrm{T} 2$ & 0.68 & -0.15 & -0.35 & -0.26 & -9.09 & -13.88 & -0.2 & 0.028 & 195.2 & -82.4 \\
\hline $\mathrm{L} 9 \times \mathrm{T} 2$ & 0.24 & 0.31 & 0.03 & 0.57 & 9.28 & 11.28 & 0.13 & -0.033 & $-619.1 *$ & -255.0 \\
\hline $\mathrm{L} 10 \times \mathrm{T} 2$ & -0.63 & -0.82 & -0.31 & -0.01 & 6.36 & 7.53 & -0.03 & 0.014 & -282 & -191.5 \\
\hline $\mathrm{L} 11 \times \mathrm{T} 2$ & 0.20 & 0.14 & 0.32 & -0.09 & $12.95 *$ & 9.12 & -0.18 & 0.032 & 258.3 & -430.8 \\
\hline
\end{tabular}


Table A9. Cont.

\begin{tabular}{|c|c|c|c|c|c|c|c|c|c|c|}
\hline \multicolumn{11}{|c|}{ (a) } \\
\hline Crosses & DYSK & DYSP & RAT1 & RAT2 & $\mathrm{CO} 1$ & $\mathrm{CO} 2$ & EASP & EPP & YLD & YLDUN \\
\hline $\mathrm{L} 12 \times \mathrm{T} 2$ & $-1.38 *$ & $-1.11 *$ & 0.11 & 0.24 & 1.49 & -3.3 & -0.16 & -0.041 & 358.6 & 438.2 \\
\hline $\mathrm{L} 14 \times \mathrm{T} 2$ & 0.28 & -0.03 & 0.24 & 0.16 & -7.84 & -14.8 & 0.07 & -0.041 & -104.4 & -39.7 \\
\hline $\mathrm{L} 15 \times \mathrm{T} 2$ & -0.38 & -0.19 & -0.43 & -0.43 & -3.18 & -10.13 & $-0.26^{*}$ & 0.019 & $557.4^{*}$ & 83.0 \\
\hline $\mathrm{L} 16 \times \mathrm{T} 2$ & 0.03 & -0.15 & -0.1 & -0.05 & 6.03 & $21.82 *$ & -0.16 & -0.034 & 102.7 & 461.0 \\
\hline $\mathrm{L} 19 \times \mathrm{T} 2$ & 0.49 & 0.14 & 0.4 & $0.87 *$ & 2.82 & $23.16^{*}$ & 0.05 & -0.045 & -166.7 & 158.3 \\
\hline $\mathrm{L} 20 \times \mathrm{T} 2$ & 0.70 & 0.77 & -0.43 & $-0.80 *$ & -11.59 & -4.88 & -0.08 & 0.036 & $600.9 *$ & -282.9 \\
\hline $\mathrm{L} 21 \times \mathrm{T} 2$ & $1.03 *$ & 1.10 * & 0.36 & 0.57 & -2.18 & -9.63 & -0.08 & -0.059 & -63.8 & 100.2 \\
\hline $\mathrm{L} 22 \times \mathrm{T} 2$ & -0.01 & -0.23 & -0.22 & -0.34 & 1.2 & 3.74 & -0.01 & -0.024 & 113.4 & 345.8 \\
\hline $\mathrm{L} 23 \times \mathrm{T} 2$ & 0.08 & 0.14 & -0.06 & 0.28 & -4.39 & 4.37 & -0.08 & -0.04 & 419.3 & 209.2 \\
\hline $\mathrm{L} 24 \times \mathrm{T} 2$ & -0.38 & -0.28 & 0.32 & -0.47 & -5.26 & -12.68 & -0.05 & 0.051 & 511 & 547.3 \\
\hline $\mathrm{L} 29 \times \mathrm{T} 2$ & 0.08 & 0.52 & 0.07 & -0.26 & -1.09 & 1.91 & $0.26^{*}$ & $0.485+$ & $-968.1^{* * *}$ & $-1380.0^{* * *}$ \\
\hline $\mathrm{L} 30 \times \mathrm{T} 2$ & 0.70 & 0.48 & 0.11 & 0.7 & 10.24 & 5.03 & 0.15 & 0.002 & $-618.0^{*}$ & $-832.5^{*}$ \\
\hline $\mathrm{L} 1 \times \mathrm{T} 3$ & -0.20 & -0.41 & 0.24 & 0.42 & 4.76 & 1.29 & 0 & 0.027 & 101.3 & 109.9 \\
\hline $\mathrm{L} 2 \times \mathrm{T} 3$ & 0.21 & 0.13 & 0.12 & 0.46 & -2.9 & -1.0 & -0.23 & 0.037 & 400.6 & 204.9 \\
\hline Crosses & DYSK & DYSP & RAT1 & RAT2 & $\mathrm{CO} 1$ & $\mathrm{CO} 2$ & EASP & EPP & YLD & YLDUN \\
\hline $\mathrm{L} 3 \times \mathrm{T} 3$ & -0.20 & -0.37 & -0.42 & -0.58 & -6.11 & -4.71 & -0.23 & 0.03 & 533.8 & 171.0 \\
\hline $\mathrm{L} 4 \times \mathrm{T} 3$ & -0.12 & -0.08 & -0.13 & -0.12 & 1.81 & -1.38 & 0.07 & -0.002 & 23 & 155.9 \\
\hline $\mathrm{L} 5 \times \mathrm{T} 3$ & 0.17 & -0.20 & -0.21 & -0.46 & 0.89 & 6.04 & 0.02 & 0.003 & 31.8 & -159.5 \\
\hline $\mathrm{L} 6 \times \mathrm{T} 3$ & 0.21 & 0.13 & 0.08 & 0.5 & -3.07 & 1.62 & 0.03 & -0.018 & -524.7 & -284.5 \\
\hline $\mathrm{L} 7 \times \mathrm{T} 3$ & -0.41 & -0.24 & 0.54 * & 0.25 & 1.76 & 13.75 & 0.04 & 0.007 & -295.1 & 229.3 \\
\hline $\mathrm{L} 8 \times \mathrm{T} 3$ & -0.52 & 1.13 & 0.33 & 0.38 & $17.22 * *$ & 11.12 & $0.38^{* *}$ & -0.144 & $-634.0 *$ & -119.3 \\
\hline $\mathrm{L} 9 \times \mathrm{T} 3$ & -0.04 & -0.16 & -0.05 & -0.04 & -7.4 & -9.33 & 0.02 & 0.017 & 140.6 & -463.2 \\
\hline $\mathrm{L} 18 \times \mathrm{T} 3$ & -0.16 & -0.12 & 0.04 & -0.12 & -5.86 & 5.83 & -0.08 & 0.024 & 139.8 & -299.1 \\
\hline $\mathrm{L} 19 \times \mathrm{T} 3$ & 0.34 & 0.30 & -0.42 & $-0.75 *$ & -13.4 * & $-32.3^{* *}$ & 0.00 & 0.097 & 46.2 & -342.1 \\
\hline $\mathrm{L} 20 \times \mathrm{T} 3$ & -0.45 & -0.45 & -0.38 & -0.29 & -9.28 & -15.5 & 0.00 & -0.005 & 120.9 & 46.0 \\
\hline $\mathrm{L} 21 \times \mathrm{T} 3$ & 0.01 & -0.12 & -0.21 & -0.41 & -2.49 & 3.3 & 0.13 & 0.052 & -88.8 & -139.0 \\
\hline $\mathrm{L} 22 \times \mathrm{T} 3$ & -0.41 & -0.08 & 0.2 & 0.42 & 4.14 & 10.4 & 0.00 & 0.06 & 390.6 & 391.1 \\
\hline $\mathrm{L} 23 \times \mathrm{T} 3$ & -0.58 & -0.58 & 0.12 & -0.08 & $18.06^{* *}$ & 14.8 & -0.12 & 0.013 & -34.9 & 55.7 \\
\hline $\mathrm{L} 24 \times \mathrm{T} 3$ & $1.21 *$ & $1.13^{*}$ & -0.13 & 0.42 & 4.18 & 6.1 & -0.04 & -0.099 & -101.4 & 169.2 \\
\hline $\mathrm{L} 25 \times \mathrm{T} 3$ & 0.59 & 0.51 & -0.38 & -0.08 & 0.43 & 4.2 & -0.02 & 0.141 & -11 & -259.1 \\
\hline $\mathrm{L} 26 \times \mathrm{T} 3$ & -0.20 & 0.09 & -0.01 & -0.04 & 8.76 & 1.4 & -0.02 & 0.05 & -17.7 & 13.7 \\
\hline $\mathrm{L} 27 \times \mathrm{T} 3$ & 0.55 & 0.30 & 0.33 & 0.38 & -1.53 & -0.8 & -0.06 & -0.072 & -59.7 & -53.1 \\
\hline $\mathrm{L} 28 \times \mathrm{T} 3$ & -0.54 & -0.66 & -0.01 & 0.17 & 8.64 & 16.0 & -0.27 & -0.034 & 18.3 & 183.6 \\
\hline $\mathrm{L} 29 \times \mathrm{T} 3$ & 0.17 & 0.05 & 0.37 & 0.25 & 1.6 & -9.1 & 0.07 & $-0.3^{* * *}$ & -117.5 & 429.2 \\
\hline $\mathrm{L} 30 \times \mathrm{T} 3$ & 0.55 & 0.51 & 0.29 & -0.29 & -4.32 & 2.5 & -0.02 & -0.006 & -174.6 & 180.3 \\
\hline SCASE & 0.50 & 0.47 & 0.24 & 0.37 & 6.54 & 10.8 & 0.12 & 0.091 & 286.4 & 346.2 \\
\hline$S E\left(S_{i j}-S_{k i}\right)$ & 1.83 & 1.67 & 0.9 & 1.1 & 23.1 & 35.2 & 0.5 & 0.3 & 1053.0 & 1251.1 \\
\hline \multicolumn{11}{|c|}{ (b) } \\
\hline Crosses & DYSK & DYSP & PL HT & EHT & HUSK & PASP & EASP & EPP & YLD & \\
\hline $\mathrm{L} 29 \times \mathrm{T} 1$ & -0.44 & -0.85 & 6.74 & 1.95 & -0.24 & -0.20 & -0.17 & $0.086^{*}$ & $950.8 * *$ & \\
\hline $\mathrm{L} 6 \times \mathrm{T} 2$ & -0.74 & -0.66 & $11.15^{* *}$ & 5.46 & -0.11 & -0.05 & 0.07 & 0.005 & $760.9 *$ & \\
\hline $\mathrm{L} 9 \times \mathrm{T} 1$ & -0.57 & -0.39 & 3.35 & 5.45 & -0.29 & -0.17 & -0.33 & -0.022 & 718.3 * & \\
\hline $\mathrm{L} 28 \times \mathrm{T} 1$ & -0.73 & -0.72 & 1.52 & 0.49 & -0.06 & -0.03 & -0.08 & 0.031 & $694.9 *$ & \\
\hline $\mathrm{L} 30 \times \mathrm{T} 1$ & -0.94 & -0.68 & $8.93 *$ & $7.57^{*}$ & 0.13 & 0.18 & 0.01 & -0.072 & 652.2 & \\
\hline $\mathrm{L} 24 \times \mathrm{T} 2$ & -0.87 & -0.70 & 2.48 & 6.54 & -0.13 & -0.15 & -0.10 & 0.035 & 547.3 & \\
\hline
\end{tabular}


Table A9. Cont.

\begin{tabular}{|c|c|c|c|c|c|c|c|c|c|}
\hline \multicolumn{10}{|c|}{ (b) } \\
\hline Crosses & DYSK & DYSP & PL HT & EHT & HUSK & PASP & EASP & EPP & YLD \\
\hline $\mathrm{L} 30 \times \mathrm{T} 3$ & 0.31 & 0.34 & 2.35 & -1.79 & -0.15 & $-0.26 *$ & 0.02 & $0.079 *$ & 180.3 \\
\hline $\mathrm{L} 8 \times \mathrm{T} 1$ & -1.32 & $-0.93 *$ & 5.64 & 6.24 & -0.14 & -0.09 & -0.13 & -0.025 & 201.6 \\
\hline $\mathrm{L} 3 \times \mathrm{T} 3$ & -0.19 & 0.01 & -1.15 & -1.04 & 0.12 & -0.03 & -0.11 & 0.012 & 171.0 \\
\hline $\mathrm{L} 29 \times \mathrm{T} 2$ & 0.26 & 0.67 & $-18.25^{* * *}$ & $-12.95^{* * *}$ & $0.33^{* *}$ & $0.27^{*}$ & 0.15 & $-0.166^{* * *}$ & $-1379.9 * * *$ \\
\hline $\mathrm{L} 28 \times \mathrm{T} 2$ & $0.97 *$ & 1.05 * & -3.60 & -1.25 & 0.08 & 0.25 * & $0.30 * *$ & -0.013 & $-878.4 * *$ \\
\hline SCASE & 0.49 & 0.44 & 4.38 & 3.45 & 0.13 & 0.12 & 0.12 & 0.039 & 346.2 \\
\hline $\mathrm{SE}\left(\mathrm{S}_{\mathrm{ij}}-\mathrm{Sk}_{\mathrm{i}}\right)$ & 1.93 & 1.70 & 15.35 & 12.22 & 0.42 & 0.31 & 0.45 & 0.12 & 1251.1 \\
\hline
\end{tabular}

(a) ${ }^{*}, * *, * *,+$ significant at $p<0.05,0.01,0.001$ and 0.0001 levels, respectively. DYSK $=$ days to $50 \%$ silking, DYSP $=$ days to $50 \%$ anthesis, RAT1 and RAT2 $=$ Striga damage rating (scale of 1-9) at 8 and $10 \mathrm{WAP}$, respectively, $\mathrm{CO} 1$ and CO2 = Striga emergence count at 8 and $10 \mathrm{WAP}$, respectively, EASP $=$ ear aspect (score at a scale of 1-5), EPP $=$ ears per plant, YLD and YLDUN = grain yield $(\mathrm{kg} / \mathrm{ha})$ under Striga-infested and non-infested conditions, respectively. (b) ${ }^{*}, * *, * * *,+$ significant at $p<0.05,0.01,0.001$ and 0.0001 levels, respectively. DYSK $=$ days to $50 \%$ silking, DYSP = days to $50 \%$ anthesis, PLHT = plant height $(\mathrm{cm}), \mathrm{EHT}=$ plant height from base to the node of the ear $(\mathrm{cm})$, HUSK = the degree of the husk covering the tip of the ear using a scale of 1 to 5 , PASP = qualitative observation of plant ideotype rated using a scale of 1 to 5, EASP = ear aspect (rating at a scale of 1-5), EPP = ear per plant and YLD = grain yield $(\mathrm{kg} / \mathrm{ha})$.

\section{References}

1. McCann, J.C. Maize and Grace: Africa's Encounter with a New World Crop, 1500-2000; Harvard University Press: Cambridge, MA, USA, 2005.

2. Ranum, P.; Peña-Rosas, J.P.; Garcia-Casal, M.N. Global maize production, utilization, and consumption. Ann. N. Y. Acad. Sci. 2014, 1312, 105-112. [CrossRef]

3. Anthony, A.O. Physical features of some selected Nigerian maize cultivars. Am. J. Plant Sci. 2014, 5, 1352-1358. [CrossRef]

4. Ekpa, O.; Palacios-Rojas, N.; Kruseman, G.; Fogliano, V.; Linnemann, A.R. Sub-Saharan African maize-based foods: Technological perspectives to increase the food and nutrition security impacts of maize breeding programmes. Glob. Food Secur. 2018, 17, 48-56. [CrossRef]

5. Setimela, P.S.; Kosina, P. Strategies for Strengthening and Scaling up Community-Based Seed Production; CIMMYT: Texcoco, Mexico, 2006.

6. Kutka, F. Open-Pollinated vs. Hybrid Maize Cultivars. Sustainability 2011, 3, 1531-1554. [CrossRef]

7. Zingore, S.; Murwira, H.K.; Delve, R.J.; Giller, K.E. Soil type, management history and current resource allocation: Three dimensions regulating variability in crop productivity on African smallholder farms. Field Crop. Res. 2007, 101, 296-305. [CrossRef]

8. Cairns, J.E.; Sonder, K.Z.; Zaidi, P.H.; Verhulst, N.; Mahuku, G.; Babu, R.; Nair, S.K.; Das, B.; Govaerts, B.; Vinayan, M.T.; et al. Maize Production in a Changing Climate: Impacts, Adaptation, and Mitigation Strategies. Adv. Agron. 2012, 114, 1-58. [CrossRef]

9. Gichuru, L.N. Breeding Investigations on Utility of Maize Streak Virus Resistant Germplasm for Hybrid Development in the Tropics (PhD) in Plant Breeding African Centre for Crop Improvement (ACCI). Ph.D. Thesis, University of Nairobi, Nairobi, Kenya, 2013.

10. Vanlauwe, B.; Tittonell, P.; Mukalama, J. Within-farm soil fertility gradients affect the response of maize to fertiliser application in western Kenya. Nutr. Cycl. Agroecosyst. 2007, 76, 171-182. [CrossRef]

11. Meseka, S.; Menkir, A.; Bossey, B.; Mengesha, W. Performance Assessment of Drought Tolerant Maize Hybrids under Combined Drought and Heat Stress. Agronomy 2018, 8, 274. [CrossRef]

12. Kim, S.K. Breeding maize for Striga tolerance and the development of a field technique. In Proceedings of the International Workshop Organized by IITA, ICRISAT, and IDRC, Ibadan, Nigeria, 22-24 August 1988; IITA: Ibadan, Nigeria, 1991.

13. Spallek, T.; Mutuku, M.; Shirasu, K. The genus Striga: A witch profile. Mol Plant Pathol. 2013, 14, 861-869. [CrossRef]

14. Kim, S.K.; Adetimirin, V.O.; Thé, C.; Dossou, R. Yield losses in maize due to Striga hermonthica in West and Central Africa. Int. J. Pest Manag. 2002, 48, 211-217. [CrossRef]

15. Emechebe, A.M.; Ellis-Jones, J.; Schulz, S.; Chikoye, D.; Douthwaite, B.; Kureh, I.; Tarawali, G.; Hussaini, M.A.; Kormawa, P.; Sanni, A. Farmers Perception of the Striga Problem And Its Control in Northern Nigeria. Exp. Agric. 2004, 40, 215-232. [CrossRef] 
16. Menkir, A.; Crossa, J.; Meseka, S.; Bossey, B.; Ado, S.G.; Obengantiwi, K.; Yallou, C.G.; Coulibaly, N.; Olaoye, G.; Alidu, H. Comparative performance of top-cross maize hybrids under managed drought stress and variable rainfed environments. Euphytica 2016, 212, 455-472. [CrossRef]

17. Menkir, A.; Meseka, S. Genetic improvement in resistance to Striga in tropical maize hybrids. Crop Sci. 2019, 59, 2484-2497. [CrossRef]

18. Kim, S.K.; Akintunde, A.Y.; Walker, P. Responses of maize, sorghum and millet host plants to infestation by Striga hermonthica. Crop Prot. 1994, 13, 582-590. [CrossRef]

19. Menkir, A.; Franco, J.; Adpoju, A.; Bossey, B. Evaluating Consistency of Resistance Reactions of Open-Pollinated Maize Cultivars to Striga hermonthica (Del.) Benth under Artificial Infestation. Crop Sci. 2012, 52, 1051-1060. [CrossRef]

20. Kim, S.K. Genetics of Maize Tolerance of Striga hermonthica. Crop Sci. 1994, 34, 900. [CrossRef]

21. Adetimirin, V.O.; Kim, S.K.; Aken'Ova, M.E. Expression of mature plant resistance to Striga hermonthica in maize. Euphytica 2000, 115, 149-158. [CrossRef]

22. Kling, J.G.; Fajemisin, J.M.; Badu-Apraku, B.; Diallo, A.O.; Menkir, A.; Melake-Berhan, A. Striga resistance breeding in maize. Breeding for Striga Resistance in Cereals. In Proceedings of the Breed Striga Resist Cereal Proc a Work, Ibadan, Nigeria, 18-20 August 1999.

23. Menkir, A. Assessment of reactions of diverse maize inbred lines to Striga hermonthica (Del.) Benth. Plant Breed. 2006, 125, 131-139. [CrossRef]

24. Hallauer, A.R.; Carena, M.J.; Filho, J.B.M. Testers and Combining Ability. In Quantitative Genetics in Maize Breeding; Springer: New York, NY, USA, 2010; pp. 383-423. [CrossRef]

25. Gutierrez-Gaitan, M.A.; Cortez-Mendoza, H.; Wathika, E.N.; Gardner, C.O.; Oyervides-Garcia, M.; Hallauer, A.R. Testcross Evaluation of Mexican Maize Populations1. Crop Sci. 1986, 26, 99. [CrossRef]

26. Vasal, S.K.; Srinivasan, G.; Han, G.C.; Gonzales, C.F. Heterotic patterns of eighty-eight white subtropical CIMMYT maize lines. Maydica 1992, 37, 319-327. [CrossRef]

27. Li, M.S.; Li, X.H.; Deng, L.W.; Zhang, D.G.; Bai, L.; Zhang, S.H. Comparisons of four testers in evaluating 27 CIMMYT and Chinese maize populations. Maydica 2007, 52, 173-179.

28. Matzinger, D.F. Comparison of Three Types of Testers for the Evaluation of Inbred Lines of Corn1. Agron. J. 1953, 45, 493. [CrossRef]

29. Rawlings, J.O.; Thompson, D.L. Performance Level as Criterion for the Choice of Maize Testers1. Crop Sci. 1962, 2, 217. [CrossRef]

30. Allison, J.C.S.; Curnow, R.N. On the Choice of Tester Parent for the Breeding of Synthetic Varieties of Maize (Zea mays L.)1. Crop Sci. 1966, 6, 541. [CrossRef]

31. Hallauer, A.R.; Miranda Filho, J.B. Quantitative Genetics in Maize Breeding; Iowa State University Press: Iowa City, IA, USA, 1988.

32. Russell, W.A. A Comparison of Five Types of Testers in Evaluating the Relationship of Stalk Rot Resistance in Corn Inbred Lines and Stalk Strength of the Lines in Hybrid Combinations. Crop Sci. 1961, 1, 393. [CrossRef]

33. Sprague, G.F.; Tatum, L.A. General vs. Specific Combining Ability in Single Crosses of Corn1. Agron. J. 1942, 34, 923. [CrossRef]

34. Guimarães, L.J.; Miranda, G.V.; DeLima, R.O.; Maia, C.; Oliveira, L.R.; Souza, L.V. Performance of testers with different genetic structure for evaluation of maize inbred lines. Ciênc. Rural 2012, 42, 770-776. [CrossRef]

35. Rather, A.G.; Sofi, P. Genetic analysis of yield traits in local and CIMMYT inbred line crosses using line $\times$ tester analysis in maize (Zea mays L.). Asian J. Plant Sci. 2006, 5, 1039-1042.

36. Sharma, J.R. Statistical and Biometrical Techniques in Plant Breeding, 1st ed.; New Age International: New Delhi, India, 2006; pp. 138-152.

37. Rashid, M.; Cheema, A.A.; Ashraf, M. Line $\times$ tester analysis in Basmati rice. Pak. J. Bot. 2007, 39, $2035-2042$.

38. Ceyhan, E.; Avci, M.; Karadas, S. Line $\times$ tester analysis in pea (Pisum sativum L.): Identification of superior parents for seed yield and its components. Afr. J. Biotechnol. 2008, 7, 2810-2817.

39. Hallauer, A.R.; Carena, M.J. Maize. In Cereals; Springer: New York, NY, USA, 2009; pp. 3-98. [CrossRef]

40. Fato, P.; Derera, J.; Tongoona, P.; Makanda, I.; Sibiya, J. Heterotic orientation of tropical maize inbred lines towards populations ZM523 and Suwan-1 under downy mildew infestation. Euphytica 2012, 187, 381-392. [CrossRef]

41. Pearce, C.S. Field experimentation with trees and other perennial crops. In Technical Communication, 2nd ed.; Commonwealth Agricultural Bureaux: Farnham Royal, UK, 1976. 
42. Singh, R.K.; Chaudhary, B. Biometrical Methods in Quantitative Genetic Analyses; Kalyani Publishers: New Delhi, India; Ludhiana, India, 1977; pp. 204-213.

43. SAS, I. SAS ${ }^{\circledR} 9.4$ Statements: Reference; SAS Institute Inc.: Cary, NC, USA, 2013.

44. Castellanos, J.S.; Hallauer, A.R.; Cordova, H.S. Relative performance of testers to identify elite lines of corn (Zea mays L.). Maydica 1998, 43, 217-226.

45. Kendall, M.G. The Problem of m Rankings. Ann. Math. Stat. 1939, 10, 275-287. [CrossRef]

46. Baker, R.J. Issues in Diallel Analysis. Crop Sci. 1978, 18, 533-536. [CrossRef]

47. Kim, S.K.; Winslow, M.D. Progress in Breeding Maize for Striga Tolerance/Resistance at IITA. In Proceedings of the 5th International Symposium on Parasitic Weeds, Nairobi, Kenya, 24-30 June 1991; Ransom, J.K., Ed.; IITA: Ibadan, Nigeria, 1991; pp. 494-499.

48. Efron, Y. Screening Maize for Tolerance to Striga hermonthica. Plant Breed. 1993, 110, 192-200. [CrossRef]

49. Horner, E.S.; Lutrick, M.C.; Chapman, W.H.; Martin, F.G. Effect of Recurrent Selection for Combining Ability with a Single-Cross Tester in Maize 1. Crop Sci. 1976, 16, 5-8. [CrossRef]

50. Hallauer, A.R. Relation of gene action and type of tester in maize breeding procedures. Proc. Annu. Corn Sorghum Res. Conf. 1975, 30, 150-165.

51. Karaya, H.; Njoroge, K.; Mugo, S.; Ariga, E.S.; Kanampiu, F.; Nderitu, J. Combining ability of maize (Zea mays) inbred lines resistant to Striga hermonthica (Del.) Benth evaluated under artificial Striga infestation. Afr. J. Agric. Res. 2014, 9, 1287-1295.

52. Badu-Apraku, B.; Menkir, A.; Lum, A.F. Genetic Variability for Grain Yield and Its Components in an Early Tropical Yellow Maize Population Under Striga hermonthica Infestation. J. Crop Improv. 2007, 20, 107-122. [CrossRef]

53. Badu-Apraku, B.; Oyekunle, M. Genetic analysis of grain yield and other traits of extra-early yellow maize inbreds and hybrid performance under contrasting environments. Field Crop. Res. 2012, 129, 99-110. [CrossRef]

54. Lopez-Perez, E. Comparisons among Five Different Testers for the Evaluation of Unselected Lines of Maize (Zea mays L.). Ph.D. Thesis, Iowa State University, Iowa City, IA, USA, 1979; 151p.

55. Hallauer, A.R.; Lopez-Perez, E. Comparisons among testers for evaluating lines of corn. In Proceedings of the Annu. Corn and Sorghum Research Conference, Chicago, IL, USA, 1997.

56. Keller, K.R. Comparison involving the number of, and the relationship between, testers in evaluating inbred lines of maize. Agron. J. 1949, 41, 323-331. [CrossRef]

57. Tandon, J.P.; Batra, J.N. Effect of testers on combining ability. Euphytica 1967, 16, 370-376.

58. Genter, C.F. Early generation progeny evaluation in corn. In Proceedings of the 18th Annual Hybrid Corn Industry-Research Conference, American Seed Trade Association, Washington, DC, USA, 1963; pp. 30-36. 